\title{
Seeking Alpha in the Housing Market
}

\author{
Michael LaCour-Little ${ }^{1}\left(\mathbb{D} \cdot\right.$ Jing Yang $^{1}$
}

Accepted: 23 June 2021

(C) The Author(s) 2021

\begin{abstract}
We examine short term trades in the housing market over the period 2000-2013 using nationally representative data across multiple U.S. housing markets. Such trades, often characterized as "house flipping", have gained currency in recent years with reality television shows depicting success and failure. We find evidence of returns in excess of market house price index growth (which we call alpha) during certain time periods with results that also vary across distressed versus non-distressed acquisition strategies.
\end{abstract}

Keywords House flip · Arbitrage · Distressed sales

JEL Classification $\mathrm{R} 30 \cdot \mathrm{R} 31 \cdot \mathrm{R} 20$

\section{Introduction}

In an article published on the Economist's View on May 18, 2017, Nobel Prize laureate Robert Shiller says that "by now, the notion of getting rich by flipping houses is entrenched. I searched Amazon for books on 'flipping houses' and came up with 325 hits, most written in the past few years,... many of these books make extravagant pitches and seem aimed at inspiring amateurs to plunge into risky ventures". ${ }^{1}$ An article published on the Wall Street Journal on October 12, 2017 reports that Goldman Sachs is reaching out to finance house flippers, which "reflects both the buoyancy of the residential real-estate market and the Wall Street firm's hunger for new profit engines as its core trading business remains stuck in a postcrisis slum". ${ }^{2}$ Another

\footnotetext{
1 See article titled "How Tales of 'Flippers' Led to a Housing Bubble" by Robert Shiller, at Economist's View on May 18, 2017, available from http://economistsview.typepad.com/economistsview/2017/ 05/how-tales-of-flippers-led-to-a-housing-bubble.html.

2 See article titled "Goldman Sachs to Lend to House Flippers" by Liz Hoffman and Peter Rudegeair, at Wall Street Journal on October 12, 2017, available from https://www.wsj.com/articles/goldman-sachs-tobuy-house-flipping-lender-1507826252.
}

Michael LaCour-Little

mlacour-little@fullerton.edu

Jing Yang

jyang@fullerton.edu

1 Finance Department, California State University at Fullerton, Fullerton, CA 92834, USA 
WSJ article on April 12, 2018 discloses that the real-estate listing company Zillow is entering a "risky and untested business model for the online service" by buying and flipping homes. ${ }^{3}$ In addition, a WSJ article on May 13, 2018 reports that some financial institutions are getting into a "lucrative and growing niche of finance" by providing high-interest, short-term home loans to borrowers to flip houses. ${ }^{4}$ Evidently, house flipping has increasingly been viewed as a positive strategy to "seek alpha" in the housing market. This is further supported by the later observation that "housing slowdown unnerves the fix-and-flip crowd", as reported in a WSJ on December 9, 2018, which quotes the words of Daren Blomquist (Senior Vice President at Attom): "The home flippers are a good barometer of where the market is heading...They are involved in such high and quick turnover of properties that they are hyper aware of market conditions". 5

Short term resales in the housing market are, however, notoriously costly. Transaction costs, including brokerage commissions, escrow fees, title work, and sometimes transfer taxes, easily approach $7 \%$ of sale price. In addition, any remodeling cost must be recovered over a relatively short time period. Moreover, short-term sales by owner-occupants do not enjoy the capital gains exclusion in taxation if the property is not held for at least two years and do not even qualify for long-term capital gains tax treatment if the holding period is shorter than one year.

Anecdotally, house flipping patterns have varied over both markets and time. During the housing bubble before the Great Recession (which we name as "crisis"), when credit was loose, buyers often employed high leverage with low or even zero down payments. Buyers could then quickly resell as house prices soared. On the other hand, during the crisis period flippers were attracted to REO and short-sale properties ${ }^{6}$ and generate good returns upon resale, especially when initially acquired for all-cash. ${ }^{7}$ During the rebound period, inventory was limited and first-time buyers often bid up prices as they competed with investors making all-cash offers. In this paper we examine short-term trades in housing over these three major economic regimes, as are more precisely defined later in the paper.

\footnotetext{
${ }^{3}$ See article titled "Zillow Intends to Buy and Flip Homes" by Laura Kusisto and Rolfe Winkler, at Wall Street Journal on April 12, 2018, available from https://www.wsj.com/articles/zillow-intends-to-buyand-flip-homes-1523581268.

${ }^{4}$ See article titled "Wall Street Is Getting In On the House Flipping Game" by Ryan Dezember and Peter Rudegeair, at Wall Street Journal on May13, 2018, available from https://www.wsj.com/articles/ wall-street-is-getting-in-on-the-house-flipping-game-1526227200.

${ }^{5}$ See article titled "Housing Slowdown Unnerves the Fix-and-Flip Crowd" by Ben Eisen, at Wall Street Journal on December 9, 2018, available from https://www.wsj.com/articles/housing-slowdown-unner ves-the-fix-and-flip-crowd-1544371200.

${ }^{6}$ REO (real estate owned) means that the property is owned by a lender after an unsuccessful sale at a foreclosure auction, and a shortsale is a property sale in which the net proceeds will fall short of debts secured by liens against the property.

${ }^{7}$ It is generally accepted that sales on an all-cash basis occur at discounted prices, although estimates of the magnitude of the discount vary across studies. See Rutherford et al. (2017) for work on this topic including foreclosure/REO sales.
} 
We define a house flip as a resale occurring within two years of initial property acquisition, further segmenting holding period into less than one year and less than one month. ${ }^{8}$ This definition means that about $76 \%$ of all transactions in our data are not flips. We are interested in four main questions. (1) What drive housing flips? (2) How sensitive are such sales to the owner's financial position and to local housing market conditions? (3) Do flips outperform non-flip sales in terms of price appreciation? (4) What factors affect the realized returns on these transactions?

There have been very few studies focusing on this topic, one of which is Depken et al. (2009). It provides statistical analyses on the flipping activities in Las Vegas during 1994 to mid-2007, suggesting that flip homes tend to be older and smaller than non-flip homes, and flippers usually buy the flip home with a discount and sell flip home at a premium as compared to nonflipped similar properties, although the returns vary with different home acquisition stages. Similar as in their study, we define flips based on the criterion of within-2-year resale, and find that flip returns as well as flip motivations vary across different stages of the housing cycle. We do incorporate not only statistical analyses but also regression analyses on a substantially larger sample covering 20 main cities in the U.S., and differentiate flips based on their home acquisition styles: regular sales, REOs or short sales.

Another related stream of research addresses buyers' incentives to resell houses quickly. Our definition of home flip is similar as their definition. Lin and Liu (2008) report that a liquidity/financial distress shock induces quick sale, often at a discount. Likewise, Seagraves and Gallimore (2013) find that the owners facing foreclosure tend to sell quickly while apparently caring little about sales price. Here we can address seller financial position by examining the incidence of pre-sale mortgage delinquency, among other factors.

Another stream of the literature focuses on the relationship between a property's time on market ("TOM") and realized sales prices. Chen and Rutherford (2012) provide a literature review on this topic, and summarize two competing theories. The first is the standard search theory, which suggests a positive relationship between sales price and TOM. By waiting, a seller increases the probability of finding a buyer willing to pay a higher price. ${ }^{9}$ This positive relation is sometimes described as a price-TOM tradeoff. The second is signaling theory which predicts the opposite relationship. A longer time on the market signals poor quality, leading to a negative relation between TOM and sale price. ${ }^{10}$ An alternative rationale for the negative

\footnotetext{
${ }^{8}$ Resales occurring within one month (occasionally on the same day) are sometimes referred to as "double-escrows' and are close to arbitrage transactions, i.e. simultaneously buying and selling the same asset at different prices. We regard these as requiring special expertise and later in the paper refer to them as "expert or agent flips" to distinguish them from "normal" transactions. Expert flips are rare, representing less than $1 \%$ of all transactions in our data.

9 For instance, Knight (2002) reports that the size of the price revision (that is, the list price-selling price gap) increases the TOM.

${ }_{10}$ Taylor (1999) theoretically predicts this signaling effect, which is supported by the empirical evidence in Anglin et al. (2003).
} 
relation is given in Kwok and Tse (2006): a short TOM indicates a liquid property market, which should be associated with a price premium for the liquidity value. A more recent study, He et al. (2020), demonstrates a nonlinear price-TOM relationship using a home sale sample in Virginia, with prices increasing in TOM first reflecting a positive exposure effect, and then decreasing in TOM reflecting a negative stigma effect, indicating that the price-TOM tradeoff may depend on the stages in a sale.

By construction, our data here are sales with relatively short TOM. Correspondingly, based on the literature mentioned above, if flip sales have higher returns than otherwise similar non-flip sales, the findings will support signaling/stigma theory or liquidity value theory, while the opposite findings will offer support to the search/exposure theory, and inconsistent results may appear for sales at different stages of sales. In addition, we think that the price-TOM relation may also be affected by the negotiation dynamics during a sale. When sellers are impatient (particularly for financial constrained flippers or those conducting fire sales), buyers (especially investors) might want to negotiate for lower prices. However, they would not want to bargain for a lengthy period when the market is hot, as there might be many other competing buyers, as such that the flips could end up with high prices. On the contrary, if the market is cold, they can bargain hard, leading to larger price cuts such as those in fire sales.

Extending the signaling analysis to market conditions, Anglin et al. (2003) find that when the local housing return are more uncertain, the signaling effect is stronger, implying that flips are more likely to generate high returns in more uncertain markets. Accordingly, we will also explore the relationship between flip returns and measures of uncertainty in the local housing market.

In this study, we use data created by merging public sales records with MLS data on single-family transactions. We segment time into three regimes: the housing bubble, the crisis period, and the rebound. ${ }^{11}$ We show that different factors affect flip sales during these differing economic regimes. We also compare flip sales to non-flip sales, defined as those with more than a two-year holding period. Flip sales outperform non-flip sales overall, particularly during the crisis period. Results are robust regardless of how we define flips, although stronger when the definition is resale within one year (instead of two years). Patterns for resales of properties acquired as REOs or as shortsales, however, are quite different from patterns for resales of properties acquired through regular purchase methods.

The rest of the paper proceeds as follows. The next section discusses our data broadly and the methodology used to test hypotheses. We then present descriptive statistics in the third section, regression results on drivers for flips in the fourth section, and regression results on flip performance in the fifth section. The sixth section concludes.

$\overline{11}$ More precise definitions of these time periods appear later in the text. 


\section{Data and Methodology}

We employ data from MSAs included in the S\&P Case-Shiller 20-City Home Price Index (SPCS20RSA) over the period 2000-2013. Data was generously provided by CoreLogic under an academic research grant. The data consists of a random draw of 750,000 observations of properties that experienced resale during the sample period from CoreLogic's public record data and a randomly selected sample of 750,000 property sales from CoreLogic's MLS data. ${ }^{12}$ The random selection method ensures that the time and geographical distribution of the transactions in the selected samples match those of the original complete data. We merge the two samples by matching property transaction information including property identifier, sales date, and sales price, with a match rate of over $70 \%$.

From the merged data we exclude those which do not appear to be bona fide arm's length (such as inter-family transfers) and transactions at outlier prices, defined as values greater than $\$ 5,000,000$ or lower than $\$ 25,000$. We then further merge this dataset with the Federal Housing Finance Agency ("FHFA") MSA-level house price indices data and the CoreLogic MSA-level market characteristics data by matching on zip codes and transaction year and month. The resulting dataset is further augmented with time-varying macro-economic variables, such as the slope of the yield curve, the return in equity markets, and the level of mortgage rates. We construct the following four sets of variables:

(I) Resale type indicators: we begin by categorizing observations into two major groups based on the previous owners' property holding time: (1) the "normal" sample, in which for each transaction, the previous owner held the properties for at least one month before resale; and (2) the "same-month flip" sample, in which for each transaction, the previous owner resold the property in the same month that he/she purchased it. Our reference group will be the normal sample. Essentially the "same-month flip" sample consists of transactions with expert sellers who are able to arbitrage price differences possibly through double-escrow sales. Again, this is a rare event, occurring in less than $1 \%$ of the data. It will be used to contrast the normal trades in the single family housing market. Ideally we would differentiate the two samples based on whether a resale occurs on the same day as the purchase. Unfortunately, the transaction date information in our dataset is limited to month and year, instead of complete date, thus we use the same-month transactions to identify expert flips. Our data also provides an indicator for REO and short sale ("SS"). In the normal sample we can distinguish REO sales, SS, and "regular" sales which are those not characterized as REO or SS. ${ }^{13}$ Our focus will be the normal sample excluding resales of properties acquired via REO or SS, but we also examine the subsets of properties acquired as REO and as SS separately.

\footnotetext{
12 This data does not include bulk transactions that might benefit from wholesale discounts in prices.

13 Properties not purchased via REO or short sales might went through other irregular transactions, which are unfortunately not indicated in our database, so we include them in the "regular" sample.
} 
(II) Flip variables: Using the "normal" sample, we will explore the differences between flip transactions and non-flip transactions. The flip dummy value is 1 if the transaction is a flip, and 0 if otherwise. We use a two-year holding period as the main cutoff point, as those who resell within two years will lose up to $\$ 250,000$ (\$500,000 for a married couple filing jointly) of capital gain exclusion when selling, provided that the property was their primary residence. ${ }^{14}$ Our data may, and almost certain does, include investment-oriented transactions where the owner never occupies the property as his or her principal residence. Under such circumstances, the two-year holding period is not the relevant timeframe, rather tax benefits arise if the property is held for at least one year allowing for longterm capital gains treatment. Accordingly, we create an additional flip dummy variable, the "1-year flip" indicator variable. Among other analyses, we can compare how "1-year flips" differ from other transactions. While more common than expert flips, 1-year flips are also relatively rare, representing about $8 \%$ of all transactions in our data. Given the availability of listing date from the MLS data, we are also able to examine transactions listed for resale within the 1-year or 2-year window of purchase, regardless of whether they are eventually sold within those timeframes. We characterize these transactions as apparently motivated to be short-term resales, even though some of them are not succeeded. ${ }^{15}$ We characterize these with a "flip attempt" dummy variable, which takes the value of 1 if the property is listed for resale within 2 years of purchase, and a "1-year flip attempt" dummy variable, which takes the value of 1 if the property is listed for resale within 1 year of purchase. We also define a sale as a "fire sale" if its listing time and sale time are within the same month and sale price is less than $75 \%$ of the purchase price of the house. Fire sales, as one might expect, stay on the market for a very short period of time (less than one month) and transact at quite low prices (about $\$ 222,000$ on average in our data).

(III) Performance measurement variables: We evaluate the performance of a house sale transaction on multiple dimensions. (1) Capital gain speed, which is the capital gain rate (that is, the difference between the sale price and the purchase price divided by the purchase price) divided by the number of months held; (2) Abnormal capital gain speed, that is, the difference between capital gain speed and the change in the FHFA MSA level house price index during the holding period also divided by the number of months held; (3) Attempted capital gain speed, which is the attempted capital gain rate (equal to the difference between the listing price and the purchase price divided by the purchase price) divided by the number of attempted house holding months (equal to the holding months

\footnotetext{
14 Of course, we do not know anything about the seller's occupancy status or whether they claimed the property to be their primary residence for some, or all, of their ownership period.

15 Of course, a seller might list their property in ownership month 22 , expecting to need 3 months to sell and then end up selling in ownership month 23 if presented with a particularly strong offer with quick close conditions. So none of these measures are perfect and we cannot know actual seller intentions or motivations.
} 
till listing time, with the length of TOM, which is unknown when the property is listed, ignored); and (4) Attempted abnormal capital gain speed, that is, the difference between the house's attempted capital gain speed and the MSA level FHFA housing price index change rate during the attempted holding period divided by the number of attempted house holding months. Note that among our robustness tests we also adjust performance measures for estimated transaction costs and tax effects, as discussed later. In addition, we also construct variables to measure the: (5) Listing price adjustment rate, which is the difference between the sale price and the listing price, divided by the listing price; and (6) Listing price adjustment speed, which is the listing price adjustment rate divided by this house's time on market. These are measures of mark-down and speed of mark-down adjustment. ${ }^{16}$

(IV) Potential determinants for flip and flip performance: We consider the following possible determinants for housing flips and their performances: (1) Property characteristics, which include the building year, building size, and lot size. We consider only these three characteristic variables because others (such as number of stories, bedrooms, and bathrooms) have too many missing data. (2) Property loan factors, including the original LTV ratio and loan status (such as delinquent or pending foreclosure). (3) Measurements for the local MSA-level housing and mortgage market conditions, which include the MSA-level FHFA HPI (Housing Price Index $)^{17}$ annual returns at the property purchase date, listing month and sale month, and MSA-level percentages of loans that are 90-days delinquent, in foreclosure, REO, auctions, pre-foreclosure, or non-owner occupied. (4) Measures of capital market conditions, including the 3-month T-bill rate, 30-year fixed mortgage rate, term spread (calculated as the difference between the yield on the Moody's Aaa-rated long-term bonds and the three-month Treasury rate), credit spread (calculated as the difference between the yield on the Moody's Aaa-rated long-term bonds and the Baa-rated long-term bonds), yield curve (calculated as the ratio of the 10-year Treasury bond rate and the 2-year Treasury note rate), and annual return on the S\&P 500 index.

Obviously, it would be ideal to have detailed seller characteristics such as income, tax bracket, assets, ownership type, and so on. Since none of these are available, we rely on property status indicators (REO, notice of default, etc.), which we believe reasonable proxies for borrower position. Moreover, matching the public record data with the MLS data provides important additional information, including time on market, listing price adjustment, etc. All these enable us to analyze patterns to a considerably greater degree than have prior researchers done.

\footnotetext{
$\overline{16}$ Our data does not include information on rent which might affect overall investment performance. We assume that any effect on our performance comparison across sale types would be minimal, as rent levels for similar properties are generally comparable under similar market conditions.

17 FHFA constructs a standard repeat sales index using data on transactions involving the Government Sponsored Enterprises, Fannie Mae and Freddie Mac; accordingly, higher priced properties are relatively under-represented.
} 
Finally, our sample covers house resales from January 2000 to December 2013. The Great Recession is commonly known to start in the last quarter of 2007 and end at the end of the second quarter of 2009. U.S. housing markets, however, crashed earlier than the rest of the economy, with the subprime mortgage loan market beginning to collapse in the second quarter of 2007 and the US median home price beginning to decline in the middle of 2007. The housing market also rebounded later than the rest of the economy. Considering these, we define the "bubble" period as the time in our sample period prior to June 2007, the "crisis" period as in between July 2007 and September 2009, and the "rebound" period as post September 2009. ${ }^{18}$

We estimate two major types of regressions: logit models of flip probability and OLS models of investment performance. Since the decision to sell or flip a property is likely endogenous to its price appreciation, we use the predicted probability of a flip generated from the logit models in our final models of investment performance for flip and non-flip transactions.

Our first effort is to explore what determines flips or attempts to flip. We run logit regressions of flip variables on measures of arbitrage incentive (local HPI rates of change) and financial constraint (a foreclosure dummy that is 1 if any foreclosure is recorded during the house's last holding period before its resale), controlling property characteristics, local housing market conditions, and national capital market conditions. We compare results for different sample periods and different sale types. The logistic regression for house flip takes the following form:

$$
D_{\text {flip }}=a+\sum_{i=1}^{b} \beta_{i} S_{i}+\sum_{j=1}^{w} \omega_{j} F_{j}+\sum_{k=1}^{v} \gamma_{k} V_{k}+\delta
$$

where $D_{\text {flip }}$ is a flip variable, such as a flip dummy, an flip attempt dummy, 1-year flip dummy, and so on; $S$ is the set of arbitrage opportunity indicators; $F$ is the set of financial constraint indicators; $V$ contains control variables (other than arbitrage opportunity and financial constraints) that are expected to affect the flip probability, including house characteristics such as size and year built, MSA-level factors such as local mortgage foreclosure rate, and capital market conditions such as the yield curve; $\alpha$ is the intercept; $\beta_{i}(i=1, \ldots, b)$ is the coefficient for the $i$-th arbitrage opportunity variable; $\omega_{j}(j=1, \ldots, w)$ is the coefficient for the $j$-th financial constraint variable; and $\gamma_{k}(k=1, \ldots, v)$ is the coefficient for the $k$-th other control variables; and finally, $\delta$ is the error term. The sale (or listing) year fixed-effect is controlled in the flip (or flip attempt) logistic regressions.

We use these flip regressions to test the following hypothesis:

- [Hypothesis 1] Arbitrage plays a role in a flip sale during the bubble period, while financial constraints play a role in a flip sale during the crisis period.

\footnotetext{
18 Time cutoffs of housing market bubble, crisis and rebound might be defined slightly differently across studies due to their different focuses (for instance, some focus on loan defaults while we focus on housing price changes). Our results are robust to these various time-cutoff definitions.
} 
In regression (1), this is to test if the flip dummy is positively affected by arbitrage opportunity proxies during the bubble, and positively affected by the financial constraint proxies during the crisis-period.

Our second analysis examines whether flip sales outperform non-flip sales. We run regressions of performance controlling flip probability derived from the previous flip logit regressions, to see if a greater flip probability improves performance. Equation (1) will serve as the first-stage regressions for this performance analysis, and the second-stage regressions are:

$$
\text { Ret }=\alpha_{r}+\theta_{r} P_{f l i p}+\delta_{r},
$$

where Ret is a property performance measurement, $P_{\text {flip }}$ is the flip probability converted from the flip variable predicted from the first-stage logit regression; $\theta_{r}$ is the coefficient of the flip probability; and finally, $\delta_{r}$ is the error term.

We will use this performance regression to test the following hypothesis:

- [Hypothesis 2] A flip sale is more likely to generate better holding period investment performance than a non-flip property sale.

In regressions (2), this means that the flip probability positively affects the flip performance, that is, $\theta_{r}>0$.

To avoid the error-in-model problem that often arises with a two-stage approach (that is, the possible imprecision in the first stage analysis due to issues such as missing variables may affect the precision of the second stage results), we also conduct a robustness test using a one-stage performance regression method. We estimate regressions of performance variables on the flip dummies, again controlling for property characteristics, local housing and mortgage market conditions, and national capital market conditions. The regressions take the following form:

$$
R e t=\alpha^{\prime}+\theta_{r}^{\prime} D_{f i p}+\sum_{i=1}^{b} \beta_{i}^{\prime} S_{i}+\sum_{j=1}^{w} \omega_{j}^{\prime} F_{j}+\sum_{k=1}^{v} \gamma_{k}^{\prime} V_{k}+\delta^{\prime}
$$

where variables Ret, $D_{\text {flip }}, S, F$ and $V$ are defined as in Eqs. (1) and (2). The coefficients of the explanatory variables are similar as in the previous two equations, in which $\theta_{r}^{\prime}$ is the coefficient on the flip dummy and $\delta^{\prime}$ is the error term. The sale (or listing) year fixed-effect is controlled in the performance regressions that incorporate the flip (or flip attempt) dummy.

We will use this type of performance regressions to test Hypothesis 2 . In regressions (3), this means that the flip dummy positively affects the flip performance, that is, $\theta_{r}^{\prime}>0$.

\section{Descriptive Analysis}

In this section, we discuss our data and descriptive statistics. After deleting outliers and those with missing values for important variables we have a total of 532,055 paired house sales transactions in our data. This represents about $71 \%$ of all initial 
data points. In other words, an observation is with two sales of the same property. Each sale pair may be characterized based on the time lapse between them. Since we do not focus on loan performance, we exclude 85,567 transactions where the second sale is REO and 54,486 transactions where the second sale is a SS. REO and SS are distress transactions outside the scope of our analysis, except to the extent that we analyze properties acquired in that status.

The majority of sales pairs $(390,002)$ end as regular resales that were neither REO nor SS. We refer to these loans as the full sample, occasionally abbreviated as "All". Of these, 13,106 belong to the subsample of loans originally acquired as REO and 3613 were acquired as SS. The remaining 373,283 resales were acquired as regular transactions (neither REO nor SS). Descriptive statistics results appear in Table 1.

\section{Comparing REO and Short Sale Acquisitions to the Full Population}

Panel A of Table 1 compares the full sample to its REO and SS subsamples. Among all transactions, $19.5 \%$ are 2-year flips and only $0.62 \%$ are abnormal or expert flips (where a house is resold in the month of purchase). Among all transaction $23.6 \%$ are flip attempts, of which $82.9 \%$ actually succeed. Although more common than expert flips, 1-year flips are less frequent, only $7.6 \%$ of all observations and less than half of all flips. Among flip attempts, $10.6 \%$ are 1-year flip attempts (again less than half of the total). Finally, $1.3 \%$ of the sample may be characterized as fire sales.

In terms of sales timing, the substantial majority of sales occur in the bubble and the rebound periods ( $41 \%$ and $40 \%$ of the sample, respectively). In contrast, REO and SS occur primarily during the rebound period (69\% and $92 \%$, respectively). This is unsurprising as sales volumes decreased during the crisis period and there were far fewer REO and SS available pre-crisis. Properties were also purchased at different average points in time. For the full sample, the average year of purchase is 2004, whereas the REO and SS subsamples were acquired much later, on average, during 2007 and 2009, respectively. Due to these timing differences, market conditions at the point of resale are also quite different. REO and short sale subsamples transacted during noticeably worse market conditions as measured by the foreclosure rates, pre-foreclosure levels, and REO on the market, among other factors.

Poor market conditions, of course, may translate into better flip opportunities. The REO subsample has far more flips (34.8\%) compared to the total market (19.5\%). Likewise, the SS subsample also has far more flips (37.4\%). The same pattern exists whether we focus on flip-attempts, 1-year flips, or 1-year flip-attempts. In contrast, the REO and SS subsamples have fewer fire sales $(0.58 \%$ and $0.30 \%$, compared to an overall level of $1.25 \%$.

The average holding time between sales is substantially shorter for REO (37.7 months) and SS (32.0 months) than for the full sample (55.6 months). While holding periods are shorter, appreciation rates per month are greater, too. For the full sample, the average capital gain speed is $0.97 \%$ per month during the property holding period, and after subtracting the contemporaneous local HPI gain speed, the abnormal gain speed remains positive at $0.53 \%$ per month. In comparison, the 


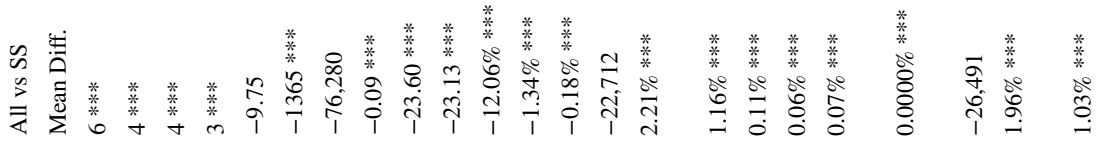

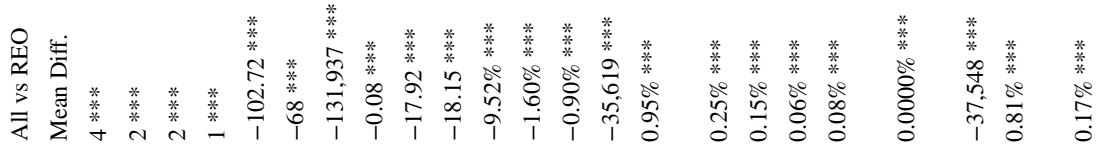

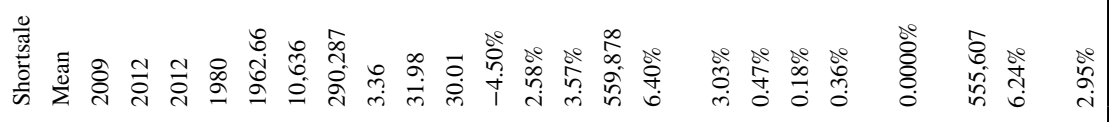
.

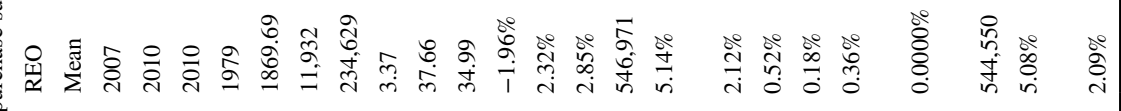
然

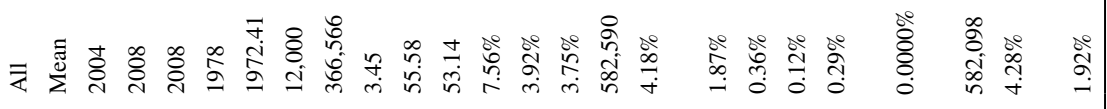

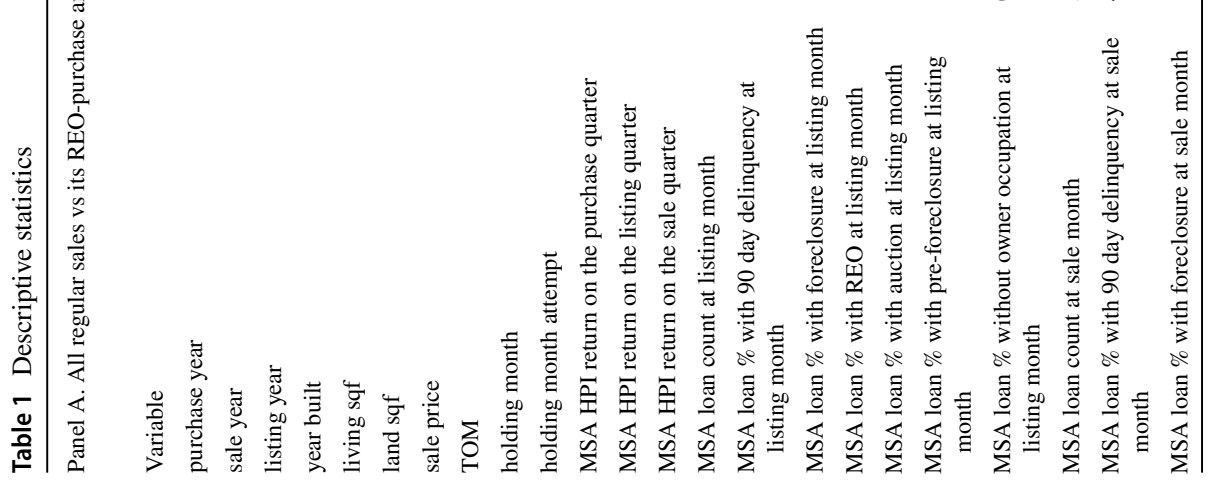




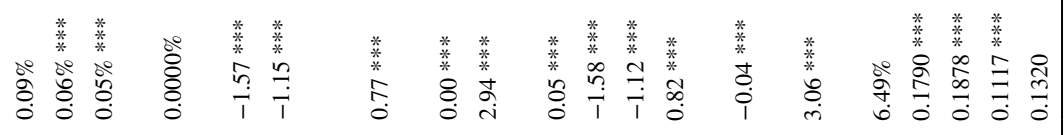

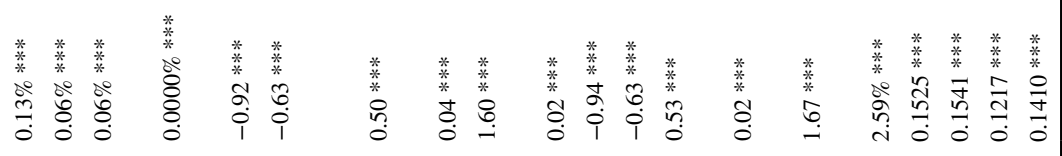

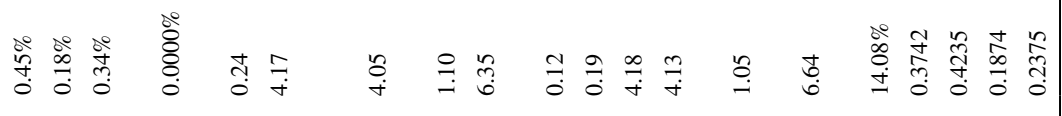

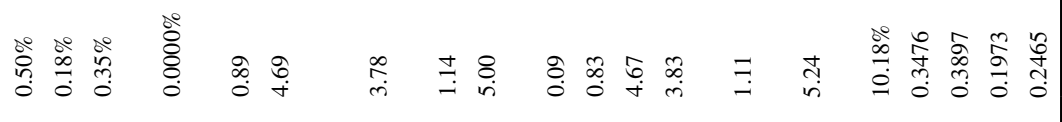

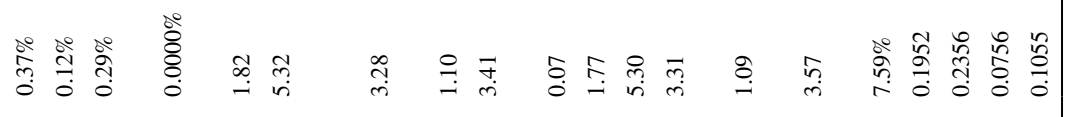

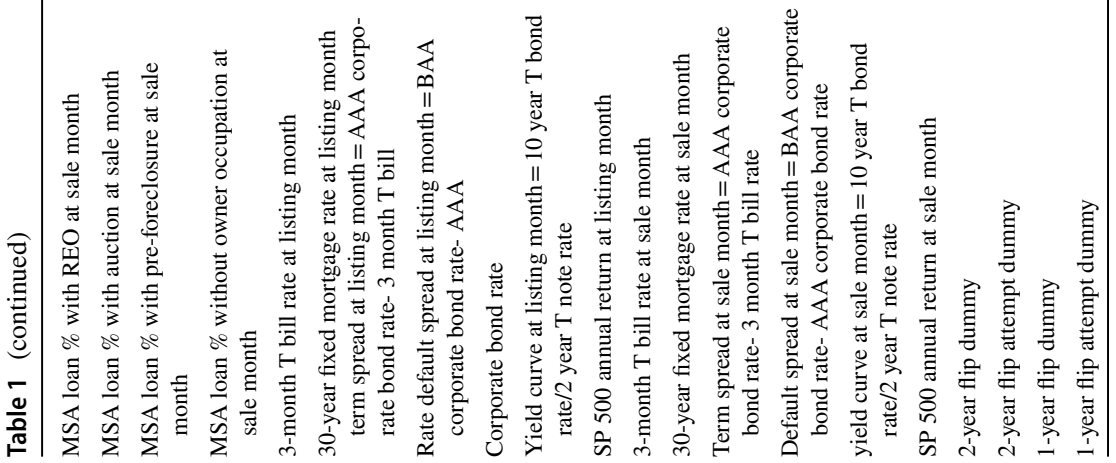




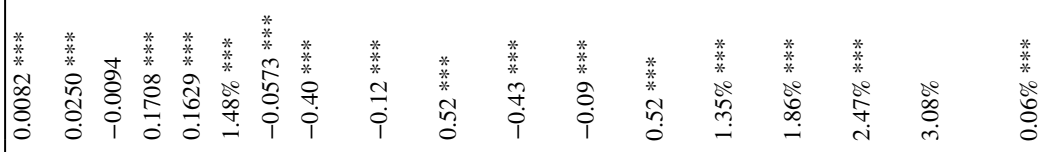

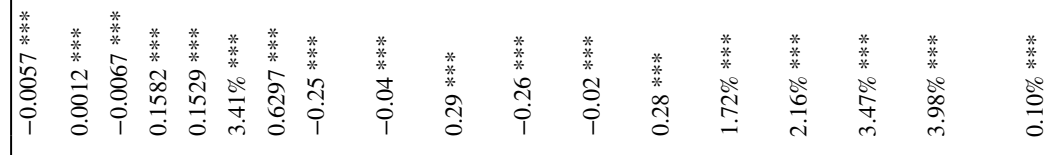

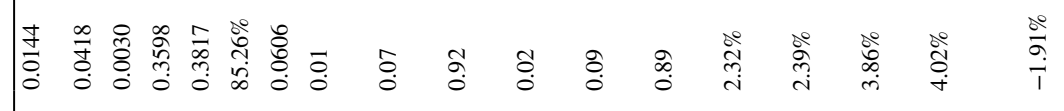

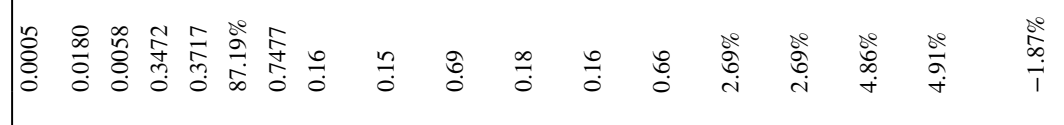

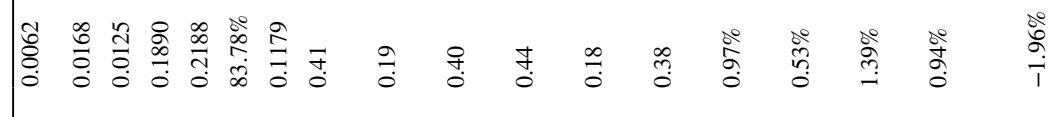

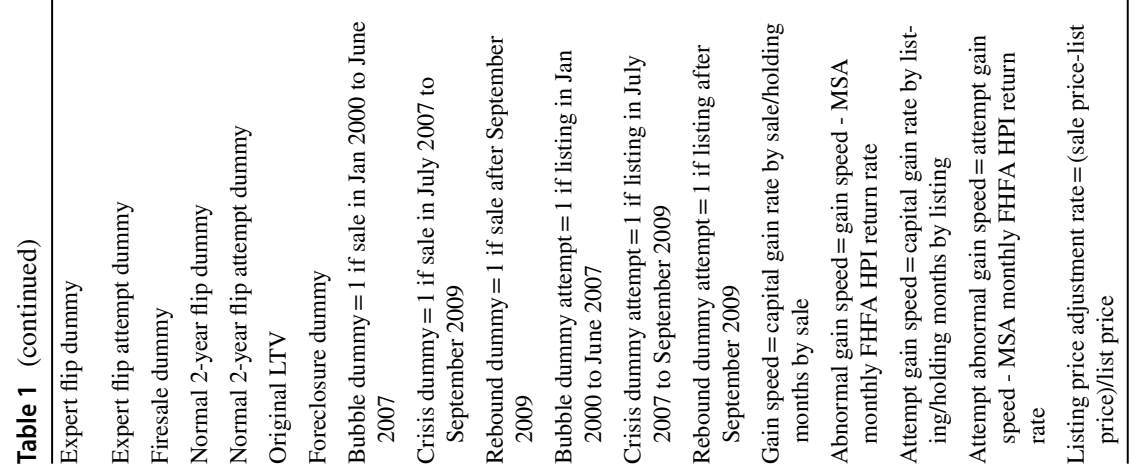




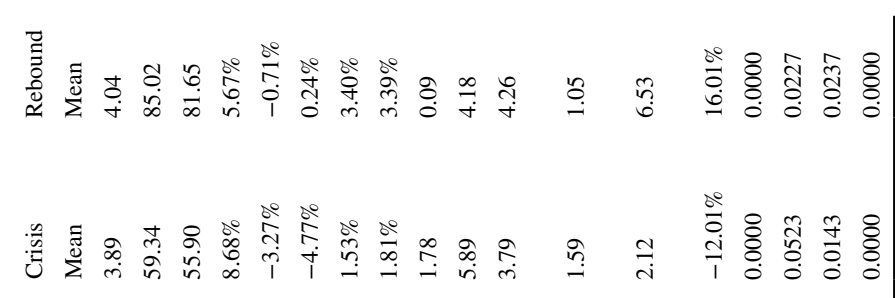

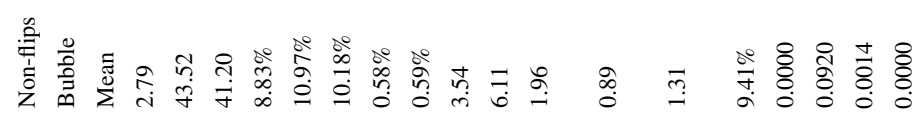

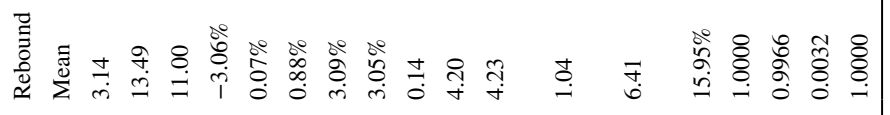

蒫

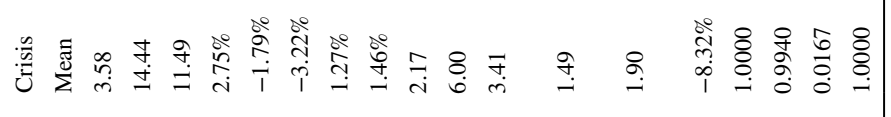
藻

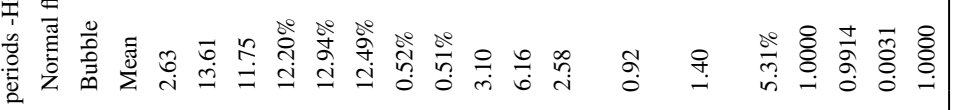

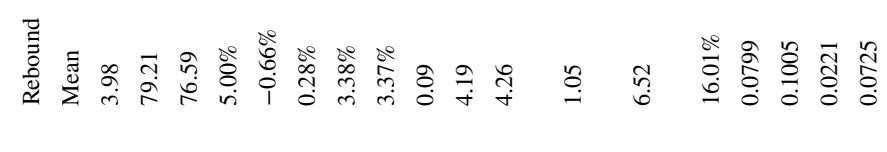

音

P. 竞

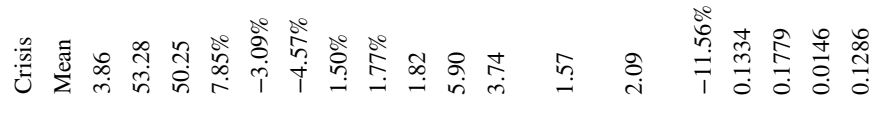
奈

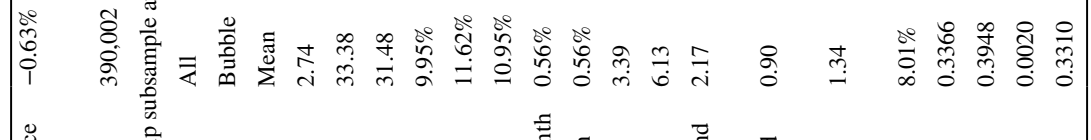

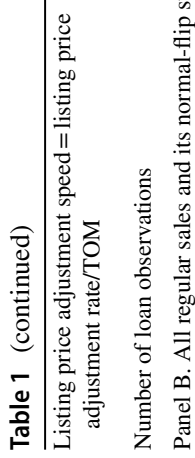

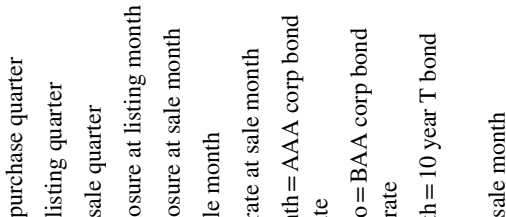

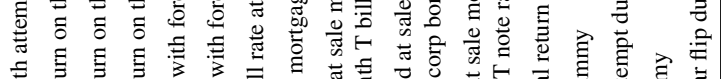

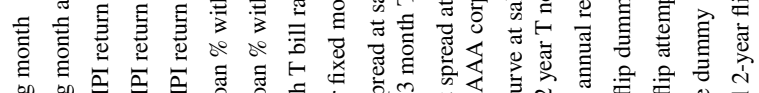

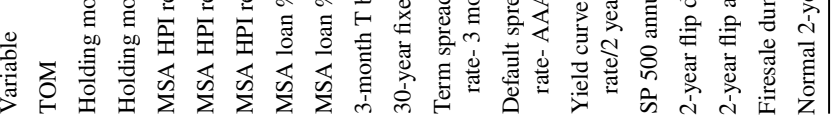




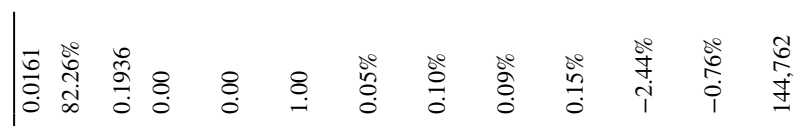

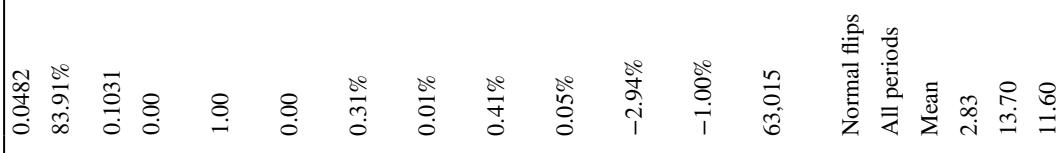

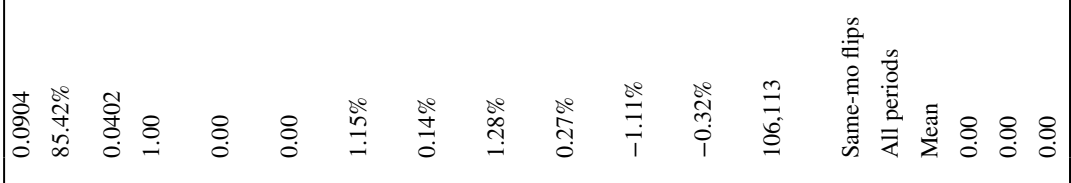

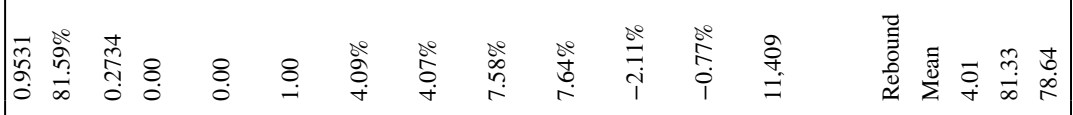

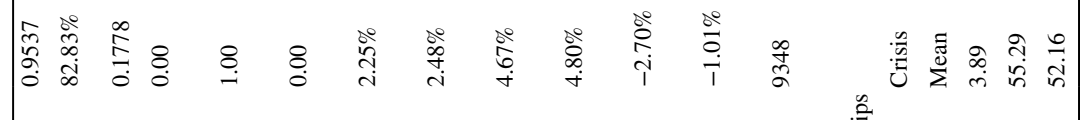

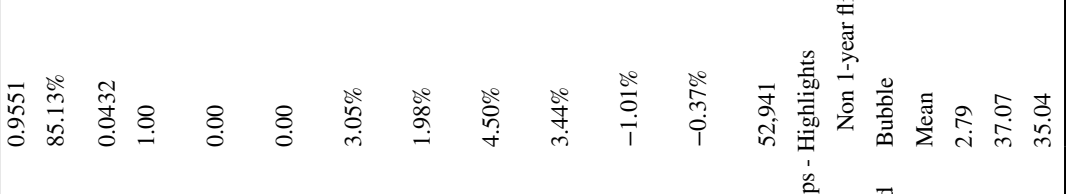

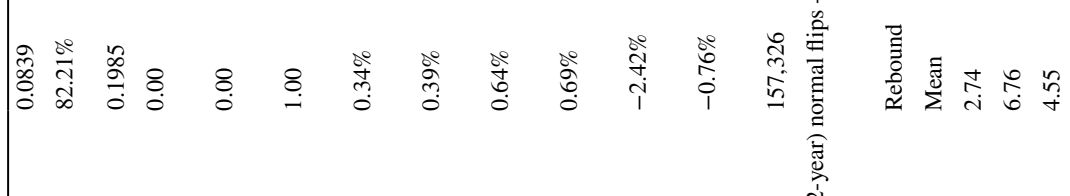

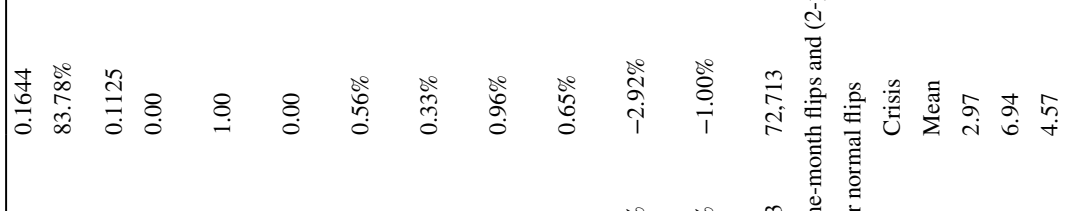

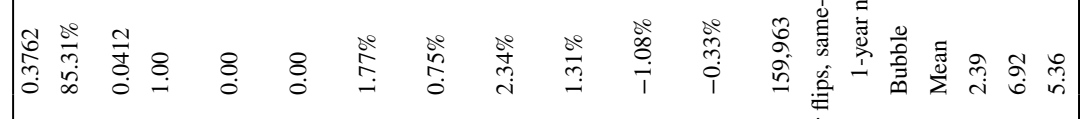

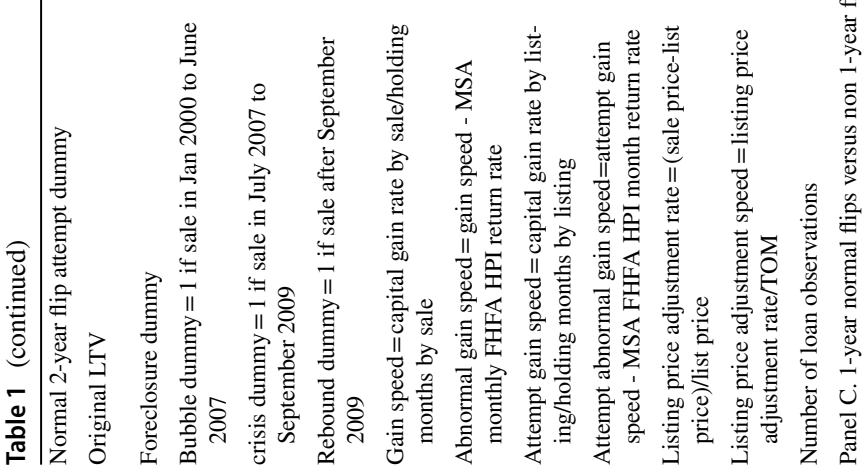

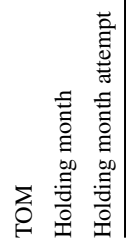




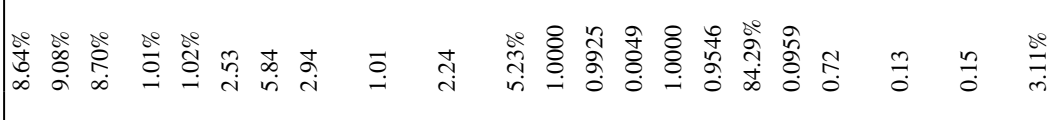

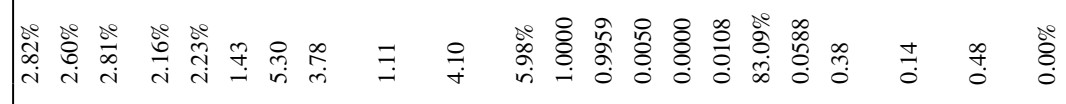

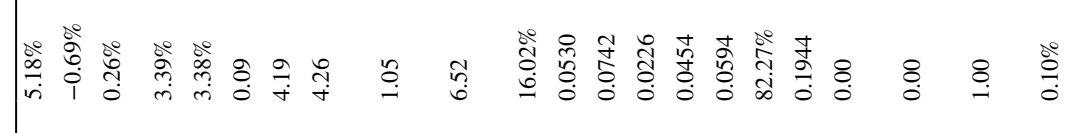

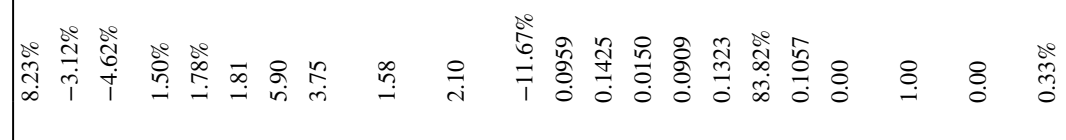

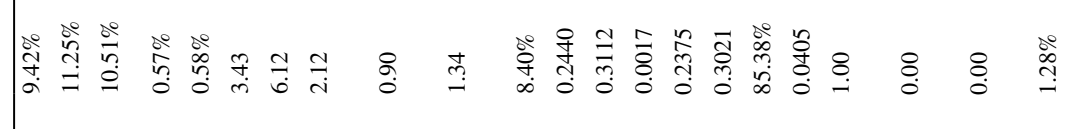

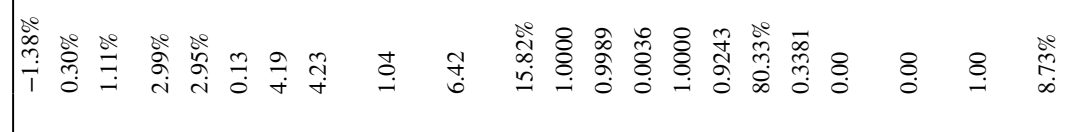

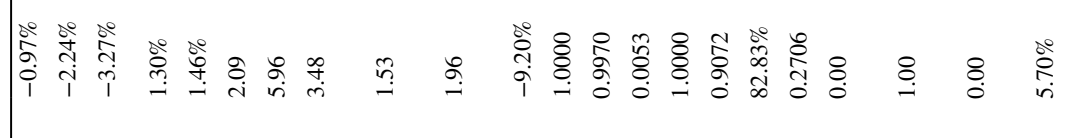

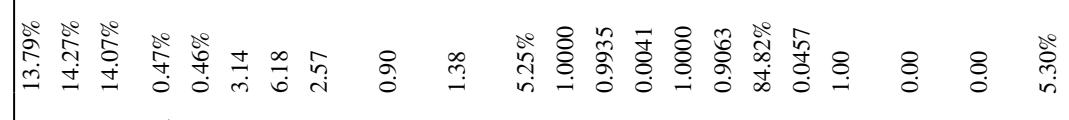

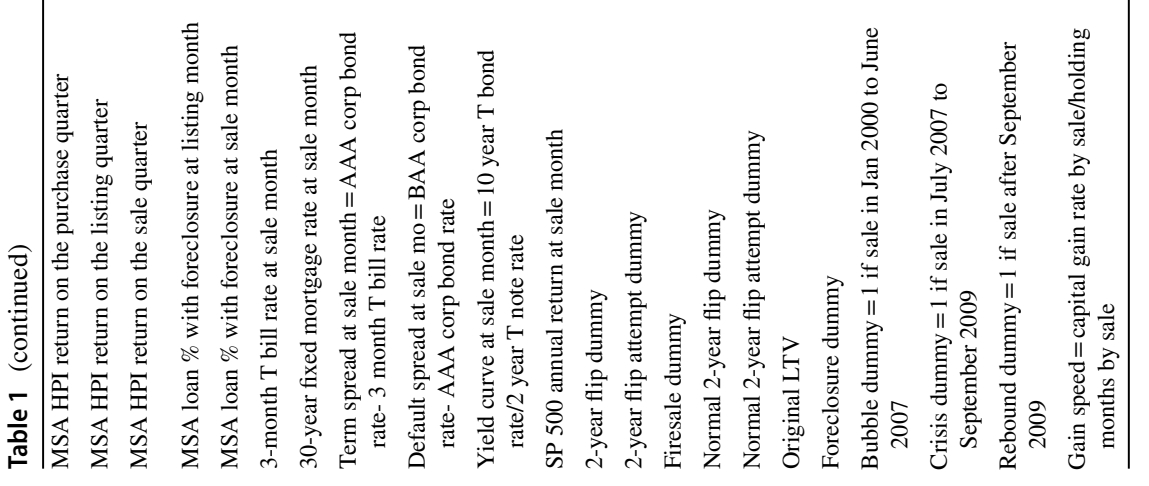




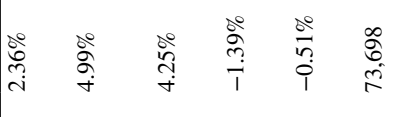

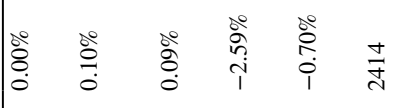

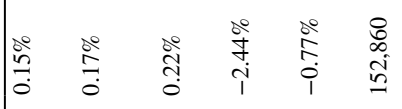

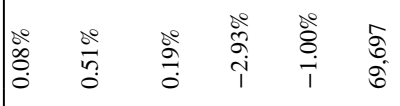

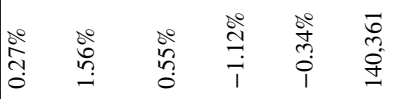

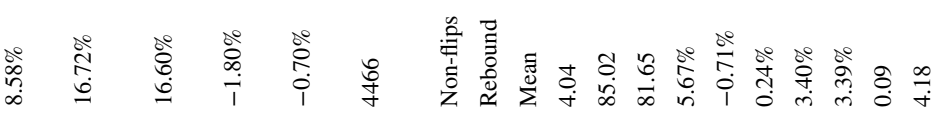

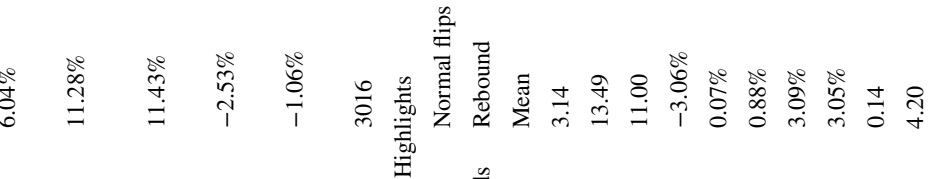

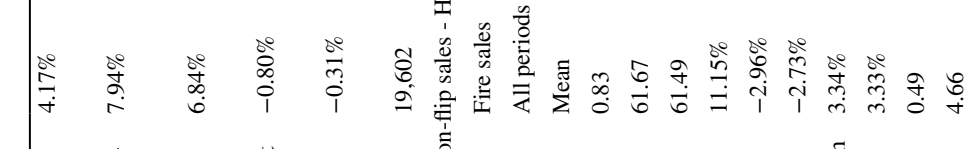

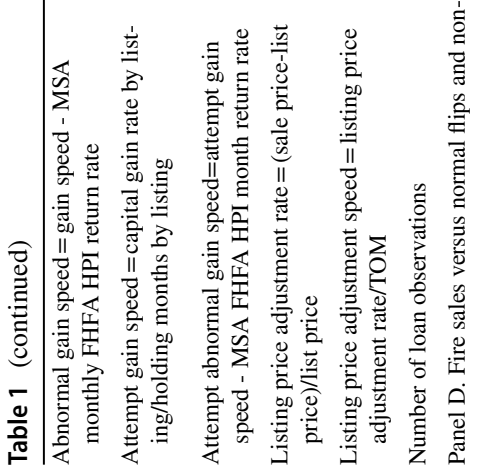

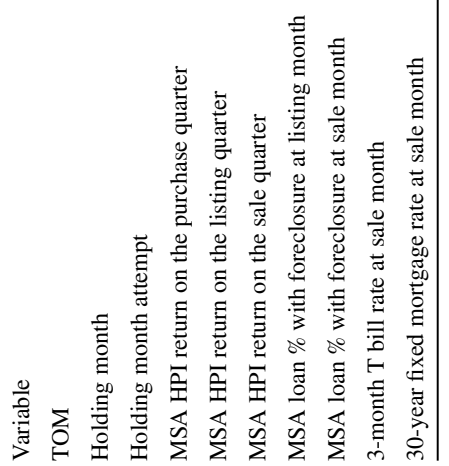




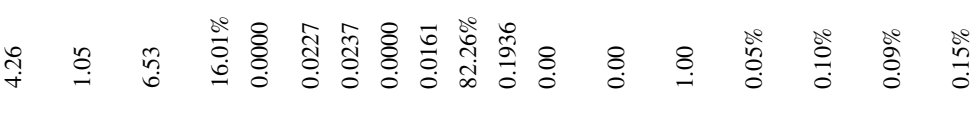

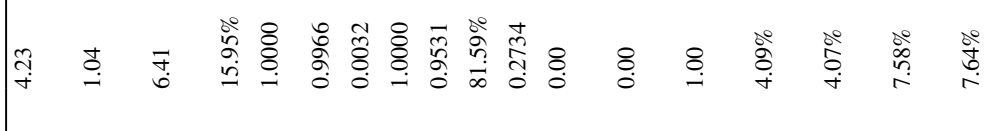

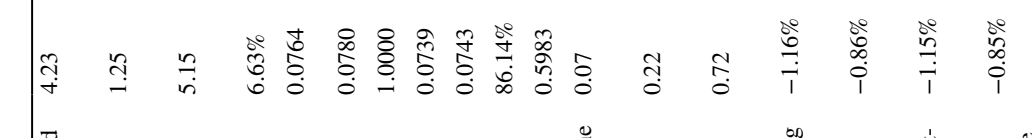

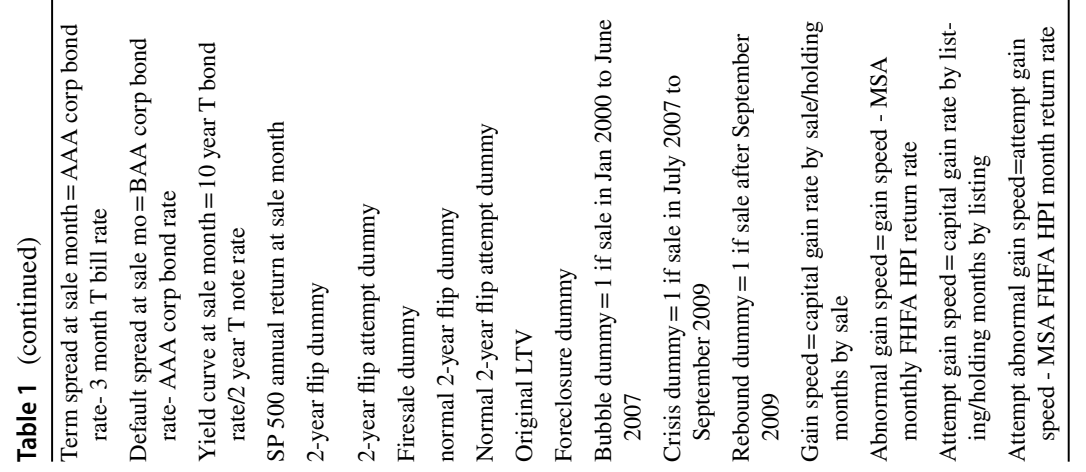




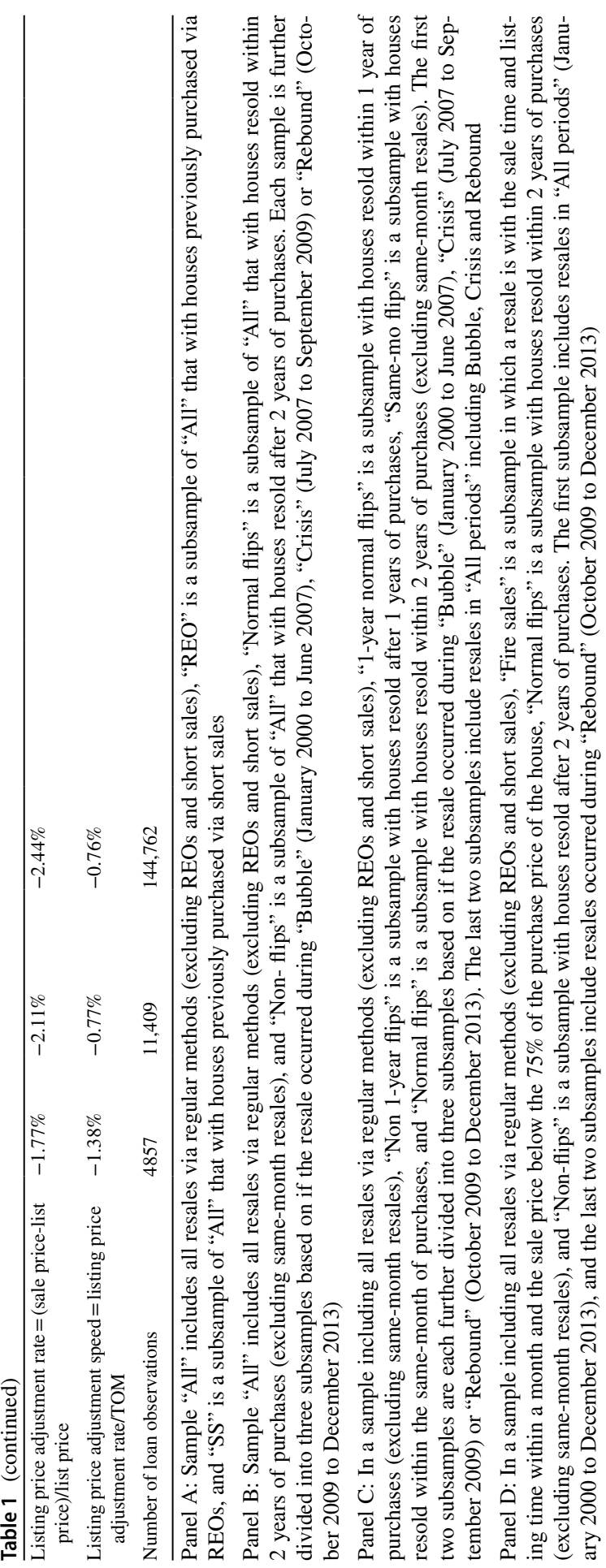


capital gain speeds for REO (2.69\% and 2.69\%) and SS (2.32\% and 2.39\%) are much faster. This result is intuitive if properties originally purchased as REO or SS are acquired at deep discounts. Results do not seem to depend on mark downs at resale, as listing price adjustment speeds are similar across the three categories. For the full sample, the sale price is adjusted downward by $1.96 \%$ from list price with similar values for REO and SS subsamples.

Figure 1 shows flip frequencies across economic regimes and acquisition types. Overall, most of the flips occurred during the bubble period, but the percentage of occurred flips during the bubble is much smaller among the REO and SS subsamples. Again, this is not surprising since most REO and SS acquisitions occurred during the crisis years and were then resold during the rebound.

These results clearly demonstrate that the resales of properties originally purchased as REO or SS exhibit dramatically different characteristics as compared to those of properties purchased as regular sales.

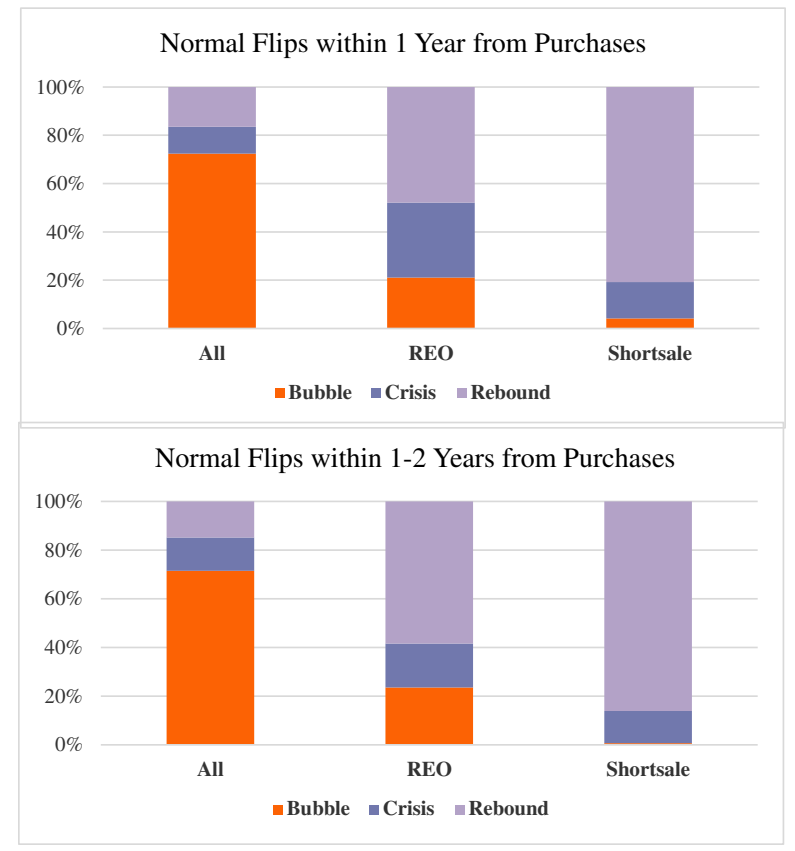

Fig. 1 Normal Flips by Period. "All" is a sample including all resales via regular methods (excluding REOs and short sales), "REO" is a subsample of "All" that with houses previously purchased via REOs, and "Shortsale" is a subsample of "All" that with houses previously purchased via short sales. "Normal flips within 1-Year from Purchases" refers to resales within 1 year of purchases (excluding samemonth resales), and "Normal flips within 1-2 Years from Purchases)" refers to resales within 1-2 years after purchases. Each sample/subsample is further divided into three subsamples based on if the resale occurred during "Bubble" (January 2000 to June 2007), "Crisis" (July 2007 to September 2009) or "Rebound" (October 2009 to December 2013) 


\section{Comparing Resales across Time Periods}

For brevity, Panel B of Table 1 highlights the results that compare regular sales, normal flips and non-flip sales across different periods. For the full sample, properties resold during the bubble period had shorter average holding time and attempted holding time. They were also listed and sold during better market conditions, i.e. when the local markets had lower frequencies of foreclosures and so on. This period may also be characterized as one during which interest rates, in general, and mortgage rates, in particular, were higher.

Sales during the bubble period were much more likely to be flips $(33.7 \%)$ than those during the crisis $(13.3 \%)$ or the rebound (8.0\%). Patterns are similar for flip attempts, normal flips and normal flip attempts. Sales were also much less likely to be fire sales in the bubble $(0.20 \%)$ than during the crisis $(1.46 \%)$ or rebound $(2.21 \%)$. Average TOM during the bubble was shorter (2.74 months versus 3.86 months during crisis and 3.98 months during rebound).

Compared to resales in the bubble and rebound periods, resales during the crisis occurred in the weakest housing markets as measured by MSA-level housing market annual returns. Macroeconomic conditions were, of course, also worse, as measured by default spreads and the stock market performance. Market conditions during the bubble period were generally better, with conditions during the rebound period in between, i.e. not as strong as during the bubble but not as weak as during the crisis. These are all what one might reasonably expect.

Overall, sales during the bubble had better performances than those in the crisis or rebound, with the fastest capital gain speed $(1.77 \%$ versus $0.56 \%$ and $0.34 \%$ per month) and abnormal capital gain speed $(0.75 \%$ versus $0.33 \%$ and $0.39 \%$ per month). This pattern holds for attempted gain speed and attempted abnormal gain speed. Sales during the crisis experienced the fastest downward price adjustments in terms of adjustment speed, while the sales in the bubble experienced the slowest.

Panel B also compares normal flips (that is, excluding same month expert flips) in the full sample across periods. Patterns are generally similar. We do find that, however, the flips during the rebound showed the best performances with the fastest capital gain speed (a remarkable $4.09 \%$ per month) and abnormal capital gain speed (4.07\% per month), as well as the fastest attempted gain speed (7.58\% per month) and attempted abnormal gain speed (7.64\% per month). In contrast, flips during the bubble have the slowest abnormal capital gain speed (1.98\% per month) and attempted abnormal gain speed (3.44\% per month). This substantial difference suggests that flips achieved the best relative outcome during the rebound and the worst relative outcome during the bubble.

We also show statistics for non-flip sales in the full sample and compare them to normal flips in the same period. As one might expect, flips have much shorter property holding periods with the pattern most evident during the rebound period, when flips were held for 13 months on average as compared to 85 months for nonflips. The difference is much smaller during the bubble period (14 months versus 44 months), suggesting greater overall housing market turnover at that time. Flips also had shorter TOM than non-flips and the difference was the largest during the rebound ( 3.1 months versus 4.0 months) and the smallest during the bubble (2.6 months versus 2.8 months). 
Note that flips do not differ too much from same-period nonflips in terms of average listing price adjustment speed. Although the former are generally sold more quickly (with shorter TOMs) than the latter, they are also sold in better markets (which are usually more active and liquid) with relatively higher listing prices (leading to better resale performances). In other words, we do not observe a tradeoff between TOM and price for flipped houses.

As shown in Panel B, flipped houses and non-flip houses are purchased/relisted/ resold under different market conditions, and these differences varied across periods, indicating different possible flip motivations. During the bubble, flipped houses were purchased and relisted/resold in much hotter markets than non-flip houses, and with lower market foreclosure rates and lower market interest rates, but also with weaker stock markets and wider term spreads (suggesting more economic uncertainty or predicted deterioration), indicating flip sellers' stronger arbitrage motivations (corresponding to lower opportunity costs of arbitrage given weaker stock markets and the smaller difficulty in arbitrage given hotter housing markets).

During the crisis, flipped houses were purchased in much colder housing markets than non-flip houses, while relisted/resold in much better housing conditions with fewer foreclosures in the markets, nevertheless also with higher market interest rates and more likelihood of foreclosure with these houses' own mortgages, indicating that flips are very likely driven by financial constraints. It seems that those distressed sellers could capture good timing to flip (they bought the houses in colder markets but flipped when the prices had declined though not by as much as in those nonflip transactions). In other words, "financial constraints" actually helped these owners to avoid larger losses during the crisis, or, they "profited from misfortunes". Another reason that they could flip before the market became worse is that most of their houses were purchased in already-poor markets, making flips in even poorer markets less costly for these sellers.

The situation during the rebound resembles that in the crisis. Flipped houses were purchased in negative-return housing markets while relisted/resold in positive-return markets, as compared to nonflipped houses which were purchased in positive-return markets while relisted in negative-return markets. Flipped houses were also sold/ listed when there were fewer foreclosures in the markets, but more likely to experience higher market interest rate and their own mortgage foreclosures which suggest the financial constraint motivations of flips. Those financially distressed sellers bought the houses in colder markets but flipped the houses when prices were increasing quickly.

The results also show that flips performed better than non-flips in terms of gain speed, abnormal gain speed, attempted gain speed and attempted abnormal gain speed. This over-performance was the weakest in the bubble. For instance, the abnormal gain speeds of flips versus non-flips houses were $4.07 \%$ versus $0.10 \%$ in the rebound, $2.48 \%$ versus $0.01 \%$ in the crisis, and $1.98 \%$ versus $0.14 \%$ in the bubble.

These descriptive statistics suggests that flips occurring during the crisis are more likely to be financially driven than those in other periods especially bubble. Flips outperformed non-flips, especially during the crisis and rebound. It seems that flips driven by momentum oriented arbitrage were not as profitable as opportunistic acquisitions at distress discounts. 


\section{1-Year Flips}

We now turn to 1-year normal flips. We compare these to sales occurring at least one year after purchase (which we call non-1-year-flip sales) across economic regimes. Results appear in Panel C of Table 1. We can see that the differences observed between 2-year flips and non-2-year-flip sales shown in Panel B also apply here with most patterns even stronger.

Compared to the non-1-year-flip sales, 1-year flips also had much shorter holding periods with the pattern most prominent during the rebound period ( 7 months for flips versus 81 months for non-flips), while least prominent in the bubble period (7 months versus 37 months). Flips also had shorter time-on-market (TOM) than non-flips with the difference most prominent during the rebound (2.74 months versus 4.01 months) and least prominent during the bubble (2.39 months versus 2.79 months). These differences are greater than for the normal 2-year flips.

1-year flips were also much more likely to experience foreclosure than non-flips during the crisis (with foreclosure rate $27.1 \%$ versus $10.6 \%$ ) and during the rebound (33.8\% versus 19.4\%). In contrast, during the bubble foreclosure rate differences $(4.57 \%$ versus $4.05 \%)$ are minimal. These contrasts are stronger than the contrasts between 2-year flips and non-2-year-flip sales. We conclude that 1-year flips are more likely to be investment-driven than non-1-year-flip sales in rising markets, and the pattern is stronger than for 2-year flips.

1-year flips also performed better than non-flips in terms of gain speed, abnormal gain speed, attempted gain speed, and attempted abnormal gain speed. This over-performance was again weakest in the bubble. For instance, the abnormal gain speed of 1-year flips and those of non-flips houses were $8.58 \%$ versus $0.15 \%$ in the rebound, $6.04 \%$ versus $0.08 \%$ in the crisis, and $4.17 \%$ versus $0.27 \%$ in the bubble. The contrast is much more substantial than when flip is defined as a resale within 2 years. Additionally, 1-year flips also experienced smaller downward price adjustments after their listing with the pattern most prominent during the rebound and least prominent during the bubble. The price adjustment speed of 1-year flips was also slightly lower than that of nonflips during the bubble and rebound, while the pattern was the opposite when flip is defined based on 2 years. This is consistent with our expectation that investors conducting 1 -year flips might have greater expertise compared to those flipping over a 2-year time horizon.

Overall results suggest that flips over either a 1-year or a 2-year time horizon are generally similar, but outcomes might differ depending on the stage in the housing market cycle.

\section{Same-Month Flips}

Where properties are resold in the same month as purchase, considerable expertise is presumably required. While we have no direct evidence, we speculate that professional real estate agents (or investors holding real estate licenses) are involved. Accordingly, we call this transaction type an "agent flip". Of 390,002 total sales, 
only 2414 are agent flips across all time periods. We compare this subsample to the normal 2-year flips subsample in the last two columns of Panel C in Table 1, and try to explore the motivations for agents to flip houses.

The results show that albeit facing more foreclosures in the market, agent flippers had much lower foreclosure rates with their own mortgage loans than normal flippers, as such financial constraint was unlikely a reason for agents to flip. Is it possible that agents believed prices were mistakenly low so it would be profitable to flip? The data shows that agent flips occurred frequently both during the bubble $(38 \%)$ and the rebound $(48 \%)$ as compared to during the crisis $(14 \%)$. This pattern differs from the concentration of normal flips occurring solely in the bubble (72\%). Presumably, the crisis period attracted professional investors who were more capable of exploiting opportunities for quick resale during the rebound than nonprofessional sellers. On the other hand, large profits over short time periods appear elusive, in part because that the rebound period generally had lower overall market returns than the bubble period. Accordingly, the average performance of agent flips is worse compared to normal flips (with an abnormal gain speed $0 \%$ as versus $2.4 \%$ per holding month). Moreover, during agent flips, listing prices apparently needed to be adjusted downward much more substantially $(-2.59 \%$ as versus $-1.39 \%$ for normal flips). Another possibility is that same-month flips occur over too short a time period to allow for any value-increasing remodeling prior to resale. In other words, chasing profits seems unlikely a reason for agents to flip. A remaining possible reason for agents to flip is that agents might be under the pressure to achieve goals for certain transaction deal numbers. ${ }^{19}$

Agent flipsshow larger and faster downward listing price adjustment than normal flips, suggesting that the price-TOM tradeoff is significant for this type of quick sales. This might be due to the fact that they were sold in much worse market conditions (hence colder markets) than normal flips, so that sellers need to cut price more significantly to sell quickly.

\section{Fire Sales}

Recall that we defined a fire sale as one consummated at a price less than $75 \%$ of the purchase price of the house (i.e. with a significant capital loss) and within one month of listing date. Such events would seem likely to be correlated with extreme financial distresses. Only about $0.32 \%$ of flips were fire sales whereas most fire sales involve properties held for more than two years (average holding length was 62 months). Since more than $70 \%$ of the fire sales occurred during the rebound, we compare them to flip and non-flip sales during that period in Panel D of Table 1.

By comparison, fire sales had much shorter TOM than did normal flips or nonflips during the rebound ( 0.83 month as versus 3.14 and 4.04 months, respectively).

\footnotetext{
19 There are also stories about flipping being used as a tactic for money-laundering. Besides, resale within one month suggests that a second buyer may have been identified at the time of the first sale, indicating that the first real estate agent may have not fulfilled his/her fiduciary duty to the original seller.
} 
Since they were concentrated in the early stage of the rebound (mainly during calendar year 2010), they occurred in relatively worse market conditions. In particular, local housing market returns were much lower $(-2.73 \%$ as versus $0.88 \%$ and $0.24 \%$ for the MSA HPI return), interest rates were higher $(0.49 \%$ as versus $0.14 \%$ and $0.09 \%$ for the 3 -month T-Bill rate), stock market was weaker (6.63\% as versus $15.95 \%$ and $16.01 \%$ for the SP500 annual return), and there were more prevalent distressed sales (including REOs, auctions, and pre-foreclosure sales).

Given the extremely short TOM (less than one month), performances of fire sales were much worse than those of non-fire sales. Compared to normal flips and non-flip sales, fire sales had faster downward price adjustment after listing than did non-fire sales (with an adjustment rate of $-1.38 \%$ per listing month as versus $-0.77 \%$ for normal flips and $-0.76 \%$ for non-flip sales), and correspondingly worse overall performance (with abnormal gain speed $-0.86 \%$ as versus $4.07 \%$ and $0.10 \%$ per holding month).

With faster downward listing price adjustment, like agent flips, fire sales exhibit a noticeable price-TOM tradeoff, which may also be driven by the fact that they were sold in cold markets with unfavorable market conditions, so the prices need to be cut severely to achieve quick sales.

\section{Unsuccessful Flips}

We also examine unsuccessful flips, that is, houses listed for resale but which failed to sell within 2 years of purchase. According to unreported statistical results, compared to successful flips most of which were listed close to 2005, those unsuccessful flips were listed mostly close to 2006 (when the crisis loomed near), a time with noticeably worse housing market conditions including worse local housing market returns and more local mortgage foreclosures / delinquencies. However, these houses were financed with mortgages with relatively low foreclosure rates and slightly lower LTVs and they were also located in more affordable areas. These results suggest that many unsuccessful flips did not succeed because they were less likely to generate arbitrage profits (as the listing quarter housing market returns were low) or because they faced less severe financial constraints reducing the sellers' incentives to apply extra effort to ensure flip success.

\section{Result on Drivers for Flips}

In this section, we report the results of flip regressions based on Eq. (1). We test Hypothesis 1 that arbitrage plays a role in flip sales at a booming housing market and financial constraints play a role in flip sales at a collapsing market. Specifically, in first set of regressions, the flip dummy is more likely to be positively affected by arbitrage opportunity proxies for resales during the bubble period but more likely to be positively affected by the financial constraint proxies for resales during the crisis-period.

Note that there are various candidate variables (listed in Table 1) that can be used as the controlling variables in Eq. (1). As expected, we find that many of these 
variables are correlated. To alleviate the multicollinearity problem, we estimate the regressions using varied sets of controlling variables, with each set including only uncorrelated variables. We find that the results are robust to the use of any specific set of variables. For brevity, we will present in this paper the results using one of these sets of controlling variables, which include property characteristics variables (year built, and living square feet), loan characteristic variable (original LTV), MSA-level variables (MSA HPI return on the purchasing quarter, and MSA loan percentage with foreclosure at listing or sale month), and capital market condition indicators (default spread and yield curve at listing or sale month).

\section{Flip Attempts}

We begin with flip attempts. Recall that these are cases in which the seller, after a relatively short holding period, lists the property for sale, whether or not the property can be sold out during one of the short holding periods defined earlier. We use the MSA-level HPI return as of the listing quarter as our proxy for arbitrage incentive. The corresponding financial constraint proxy is the foreclosure dummy which measures whether the property has a foreclosure in its individual history. Results are reported in Table 2 .

Panel A shows the results for resales purchased under any possible transaction circumstances (but over $95 \%$ of the properties were purchased regularly). The dependent variable is a flip attempt dummy, which is equal to 1 if the property is listed for resale within 2 years of purchase and 0 if otherwise. Comparing logit regression results across the three economic periods, we find that the coefficient on MSA HPI return as of listing quarter is 0.236 and -1.811 , in the bubble and rebound periods, respectively, with all estimates significant at the $1-5 \%$ levels. The variable is insignificant in the crisis period. In other words, the local housing market return at the time of listing increases the probability of a flip attempt during the bubble period, but does not affect it during the crisis, and even decreases it during the rebound. These results support our first prediction (Hypothesis 1) that the arbitrage motive for flipping is strong during the housing bubble.

We next examine the effects of our financial constraint proxy, the foreclosure dummy. The coefficient is $0.275,0.543$ and 0.194 , in the bubble, crisis and rebound periods, respectively, all significant at the $1 \%$ level. This shows that while houses experiencing foreclosure are uniformly more likely to be offered as flip sales across time periods, the influence is the largest during the crisis. Indeed, the magnitude of the coefficient during the crisis period is about or more than twice its value during the bubble and rebound. This result is consistent with the second prediction derived from Hypothesis 1, namely that financial constraints are a strong driver of flip transactions during the crisis.

Recall that we control for varied economic factors in the regressions. Interestingly, using another regression specification the results of which are untabulated, the coefficient on equity market returns (as measured by the SP500 annual return as of listing month) is -0.16 at a $5 \%$ significant level during the bubble period, but insignificant during the crisis and rebound periods. In other words, higher equity market 
returns reduce flip attempts during the bubble while having no effect in the other two periods. This also supports Hypothesis 1 that arbitrage motive plays a role as a substitute for the stock market arbitrage during the bubble, but not in other periods.

Next we turn to 1-year flip attempts, again using sales where the initial purchase could have been under any circumstance (regular, REO, or short sale). Panel B reports the logistic regression results where the dependent variable is the 1-year flip attempt dummy. We find that 1-year flip attempts are substantially more responsive during the bubble, evidenced by a much larger positive coefficient to local housing returns, than the 2-year flip attempts. In addition, the response is positive not only during the bubble period but also in the crisis period, where the effect is largest. This suggests that 1-year flips might be motivated more by arbitrage purposes than are 2-year flips. The pattern is stronger in worse market conditions (i.e. the crisis period), meaning that sellers may be acting in an effort to reduce capital losses by selling out houses quickly before prices further decline.

In the interest of brevity we do not report the results of agent flip attempts ${ }^{20}$ but note that the effect of local housing returns are very large and positive during the crisis period, suggesting that professionals reacted quickly to reduce losses during the crisis period.

We now consider how the type of purchase affects results. Panel C shows flip attempt logistic regression results for properties originally purchased as REO. Comparing results across periods, we find that the coefficient of the MSA HPI return at the listing quarter, our proxy for the arbitrage incentive, are with values of $-6.5,8.4$ and -3.8 , for the three periods, all significant at the $1 \%$ significance level. In contrast to the results discussed above when properties are mostly purchased as regular sales (shown in Panel A), local housing market returns have a negative, rather than a positive, effect on flip attempts during the bubble period. Results also differ during the crisis period, as flip attempts are positively related, rather than unrelated, to the local housing market returns. These results are inconsistent with the first prediction in Hypothesis 1 that the arbitrage motive for flips is stronger during the housing bubble than during the crisis. In other words, REOs are somehow different.

Property condition may play a role. Considerable research suggests that REO are often in poor conditions indicating that their buyers to use for primary residence might be financially constrained. During the bubble years, houses were expensive with prices generally increasing, and properties purchased via REO and then quickly resold during this period could be acquired at expensive time points, further increasing the financial burdens of their buyers, who hence face a higher pressure to resell the properties quickly. In contrast, during the crisis years, houses were generally less expensive and there were often many options from which qualified buyers could choose. Given that broad array of options, a REO buyer might well be opportunistically acquiring a property in hopes of a quick resale.

Interestingly, estimates of coefficient on our financial constraint proxy, the foreclosure dummy, are 0.28 and 0.36 , respectively, during the bubble and rebound periods, both significant at the $1 \%$ level, while insignificant in the crisis period. These suggest that financial constraint incentives were weaker during the crisis while

${ }^{20}$ Results are available from the authors on request. 


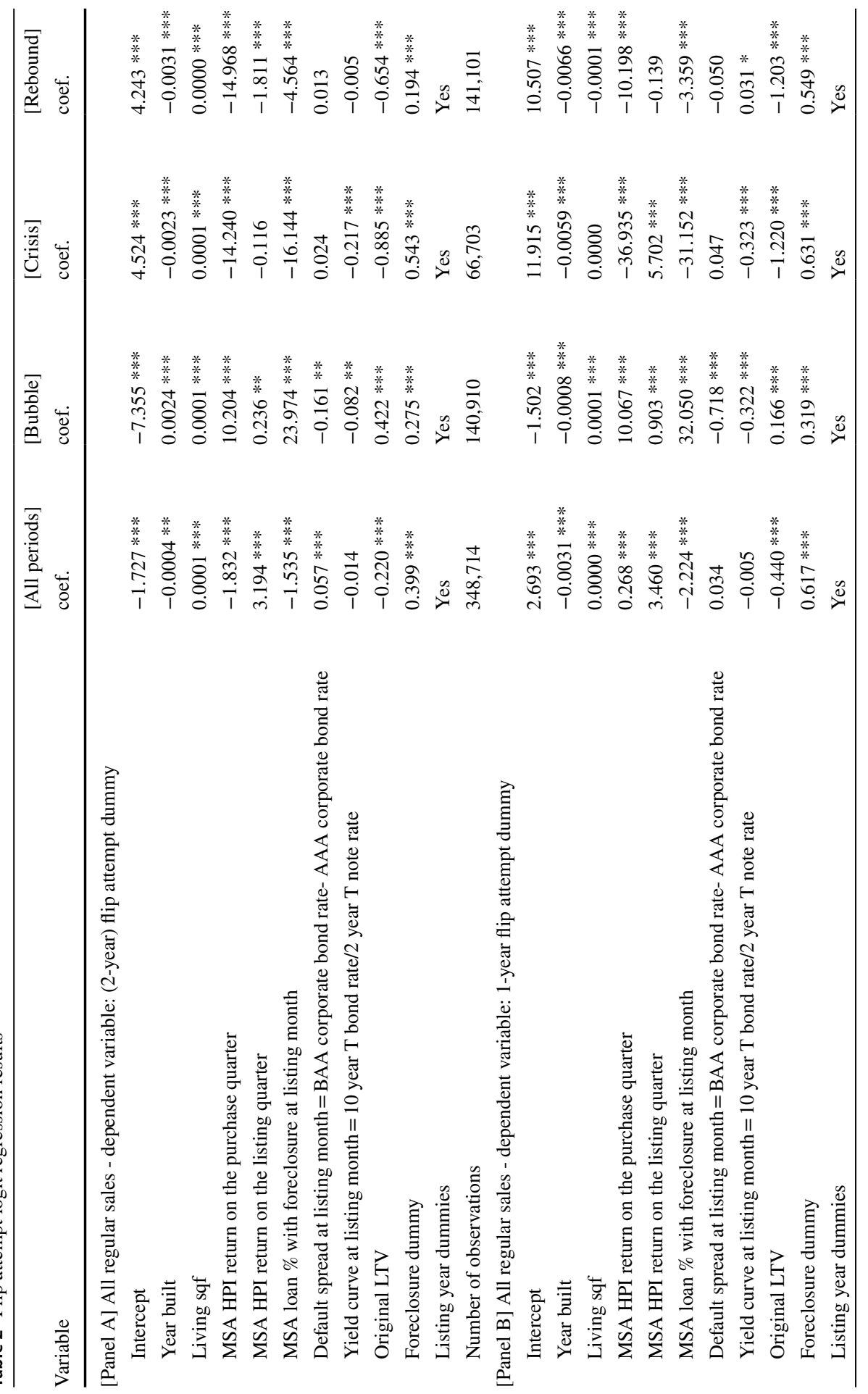




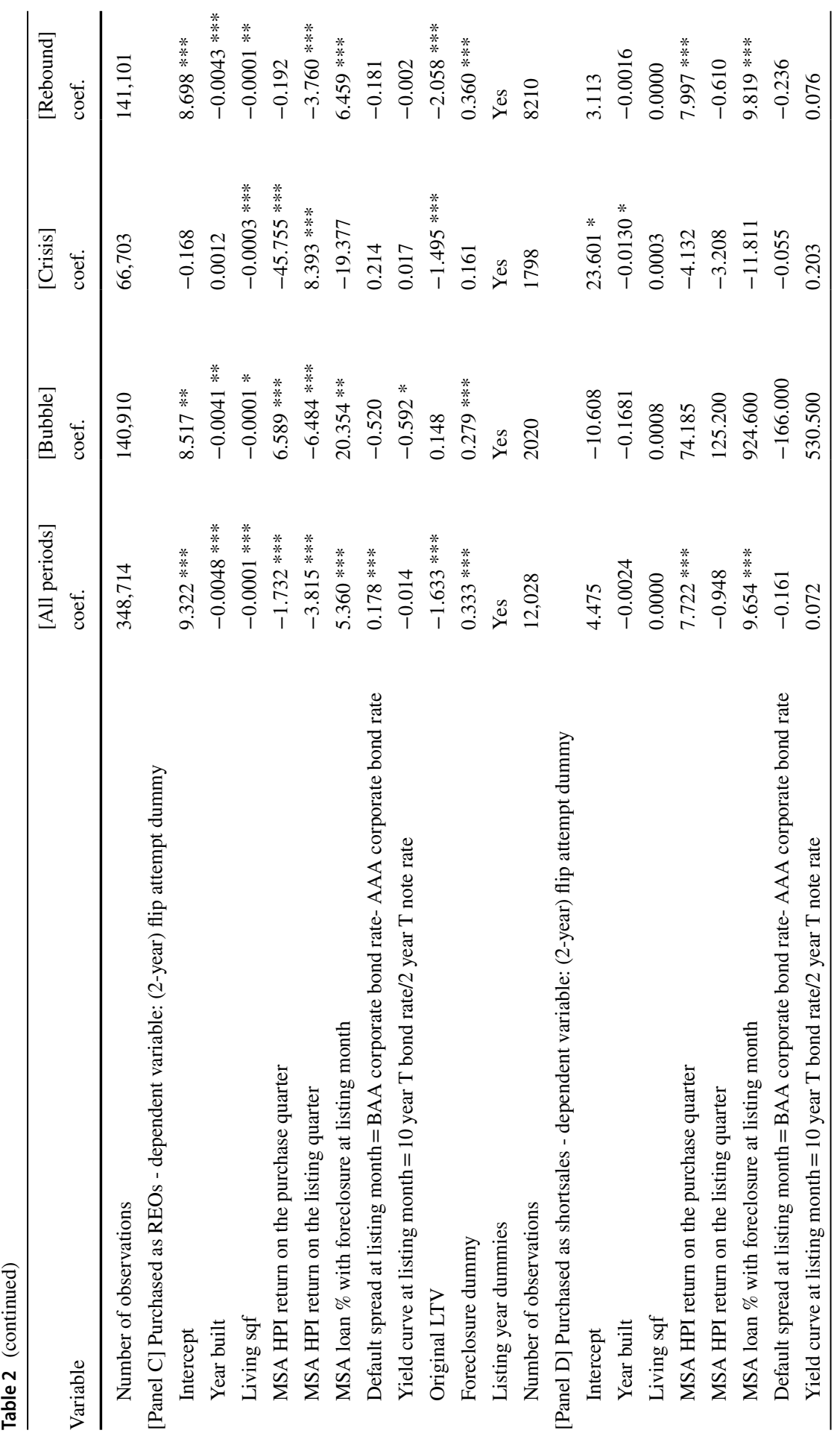




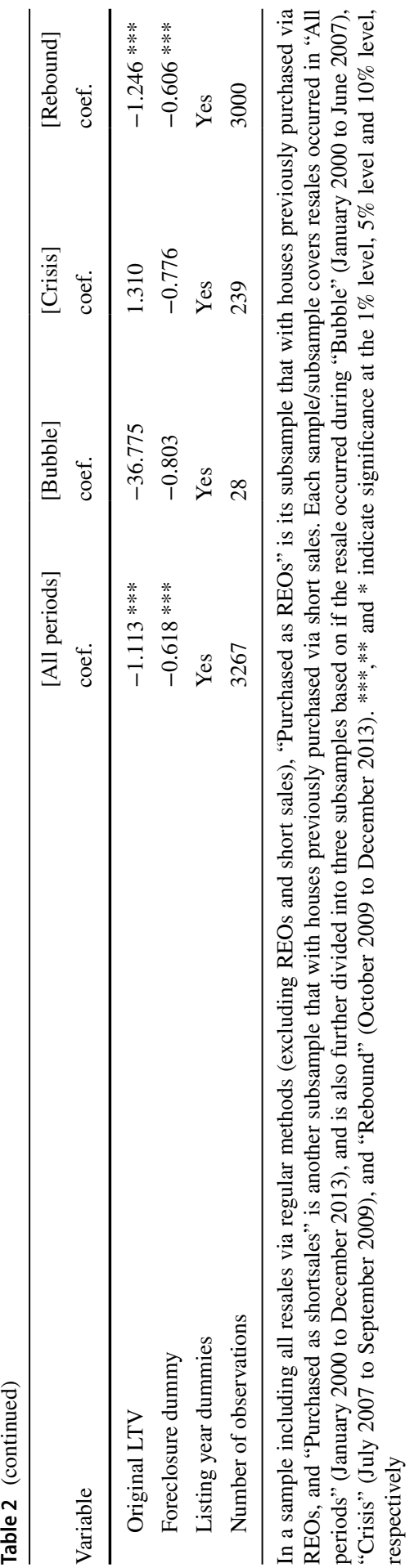


stronger during the bubble/rebound, at least for flips where properties were acquired as REO. Again, the story here is that the alternative (investment) incentives might be stronger during the crisis while weaker during the bubble and rebound.

In Panel D we report flip attempt logistic regression results for resales of properties purchased as short-sales. ${ }^{21}$ The dependent variable is the 2-year flip attempt dummy. Due to the small number of observations from the bubble and crisis periods, our discussions will focus on the rebound period. The coefficient on MSA HPI return as of the listing quarter is insignificant, but the coefficient on the foreclosure dummy is -0.61 and significant at the $1 \%$ level. A short-sale usually takes a much longer time than a regular sale due to the need for lender approval suggesting greater involvement by investment-oriented and relatively more sophisticated buyers. As a result, the financial constraint incentive is not very strong for the flips on this type of properties.

\section{Successful Flips}

Thus far we have looked only at attempted flips. We now run regressions on successful, or actual, flips. These regressions address the question that, given a demonstrated desire to sell quickly, what factors predict a success of this kind of sales? Results will be informative as to whether housing market performance not only motivates flips but also predicts success. Our key explanatory variable is the MSAlevel HPI return during the sale quarter. Recall that we previously used the MSAlevel HPI return at the listing quarter as the arbitrage incentive proxy. To distinguish the two measures, we characterize this new key variable as the "market opportunity proxy", the annual return that could be made by the current quarter. On the other hand, a more financially constrained seller will likely be impatient during the house listing period, ending up with a faster sale. Therefore, we also characterize the foreclosure dummy (which shows if any foreclosure is recorded during the house's last holding period before its resale) as the "seller impatience proxy". Results are reported in Table 3.

Panel A exhibits results for properties purchased under any circumstances across economic regimes with the dependent variables as the 2-year flip dummy. We see that the coefficients on MSA HPI return as of the sale quarter, our measure of the market opportunity, are $1.5,-3.1$ and -2.7 , in the bubble, crisis and rebound periods, respectively, all significant at the $1 \%$ level. This means that the current market return increases the chance of a successful flip during the bubble period, but not during the crisis or rebound periods. In other words, compared to what happened in the crisis or rebound periods, in the bubble period not only were flips driven more by arbitrage, but their success was also positively related to market opportunities. On the other hand, since flips were less likely driven by arbitrage in the crisis and rebound periods, market opportunities in these periods were less important. The effect of the financial constraint proxy (which we also characterize as a seller

\footnotetext{
${ }^{21}$ Short sales have by far the fewest number of observations in our data.
} 
impatience proxy), is similar to results seen earlier on when modeling flip attempts. This means that financial constraints not only motivate flips, but also increase seller impatience making flips more likely to succeed.

Regression results for 1-year flips (Panel B), 2-year flips of REO properties (Panel C) and 2-year flips of properties purchased as SS (Panel D) are also reported in Table 3. They are all generally similar to the results for flip attempts shown in Table 2. These similarities are not difficult to understand. Recall that success rates exceed $70 \%$ among 1-year flip attempts and over $80 \%$ among 2-year flip attempts. Success rates are even greater for properties purchased as REO or SS. In addition, the average TOM for all transactions (both flips and non-flips) is relatively short at about 3 months. This means that market conditions during the sale month are not much different from that during the listing month. These factors explain the similarity of results in Tables 2 and 3.

\section{Robustness Tests for Flip Drivers}

\section{Flip Responding to Lagged Housing Market Returns}

Since flips are associated with quick resales (within 2-year or 1-year of purchases), and the MSA-level FHFI HPI data is quarterly based, in our flip attempt (or flip) logit regressions, we have used the MSA HPI return of the listing (or sale) quarter as a proxy for the arbitrage incentive, assuming that with a higher local HPI return, the arbitrage incentive is stronger. We understand that an arbitrage can be lagged, that is, responding to a lagged local housing market condition, even though during the short (2-year or 1-year) time window, the lag usually cannot be too long. As a robustness test, we re-estimate the flip attempt regressions and the flip logit regressions, on the same set of independent variables except that the MSA HPI return of the listing (or sale) quarter is replaced by its 1-quarter lagged term. This can also help address the causality concern on the relations between flip and housing market returns. The results are highlighted in Table 4 - Panels A1 and A2.

Panel A1 reports the coefficient and significance of the MSA HPI return on the quarter prior to the listing quarter in each of the four flip attempt logit regressions. Regression [1] is the flip attempt regression for properties purchased under any circumstances. The coefficients are 0.362, 2.007 and -0.522 , for the bubble, crisis and rebound periods, respectively, at $1-10 \%$ significance levels. Comparing these to the coefficients of the MSA HPI return on the listing quarter reported in Panel A of Table 2, the contrast between the bubble period and the rebound period still exist, while the coefficient in the crisis period turns from insignificant to positive. In other words, during crisis, the arbitrage incentive does work at least with a lag.

Regression [2] is the 1-year flip regression for properties purchased under any circumstance, and the coefficients and significances of the MSA HPI return on the quarter prior to the listing quarter are generally in line with those of the MSA HPI return of the listing quarter reported in Panel B of Table 2, except that during the bubble, the flip attempt is not increasing in the 1-quarter lagged HPI return, although it is increasing in the current quarter HPI return, indicating that housing market 


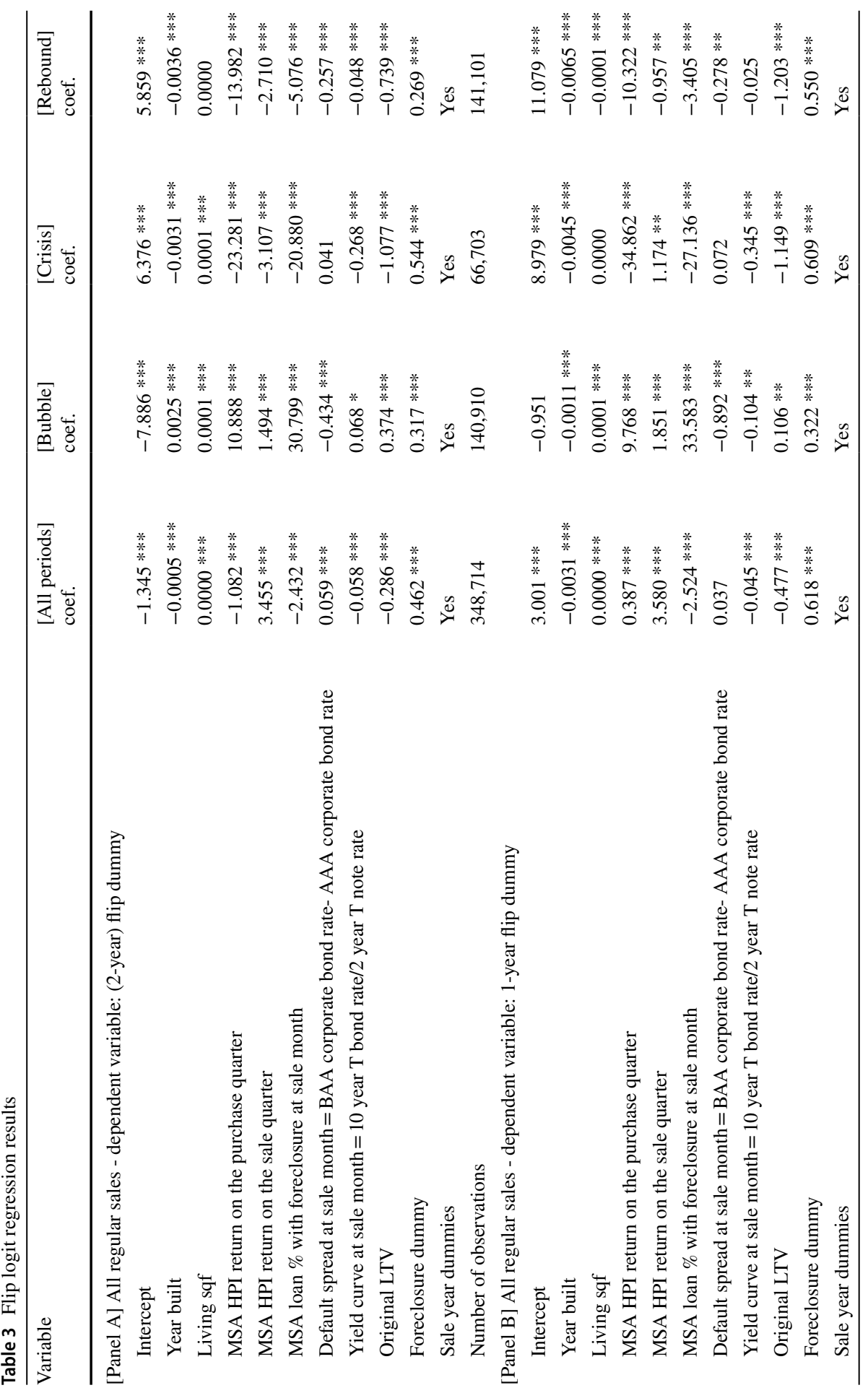




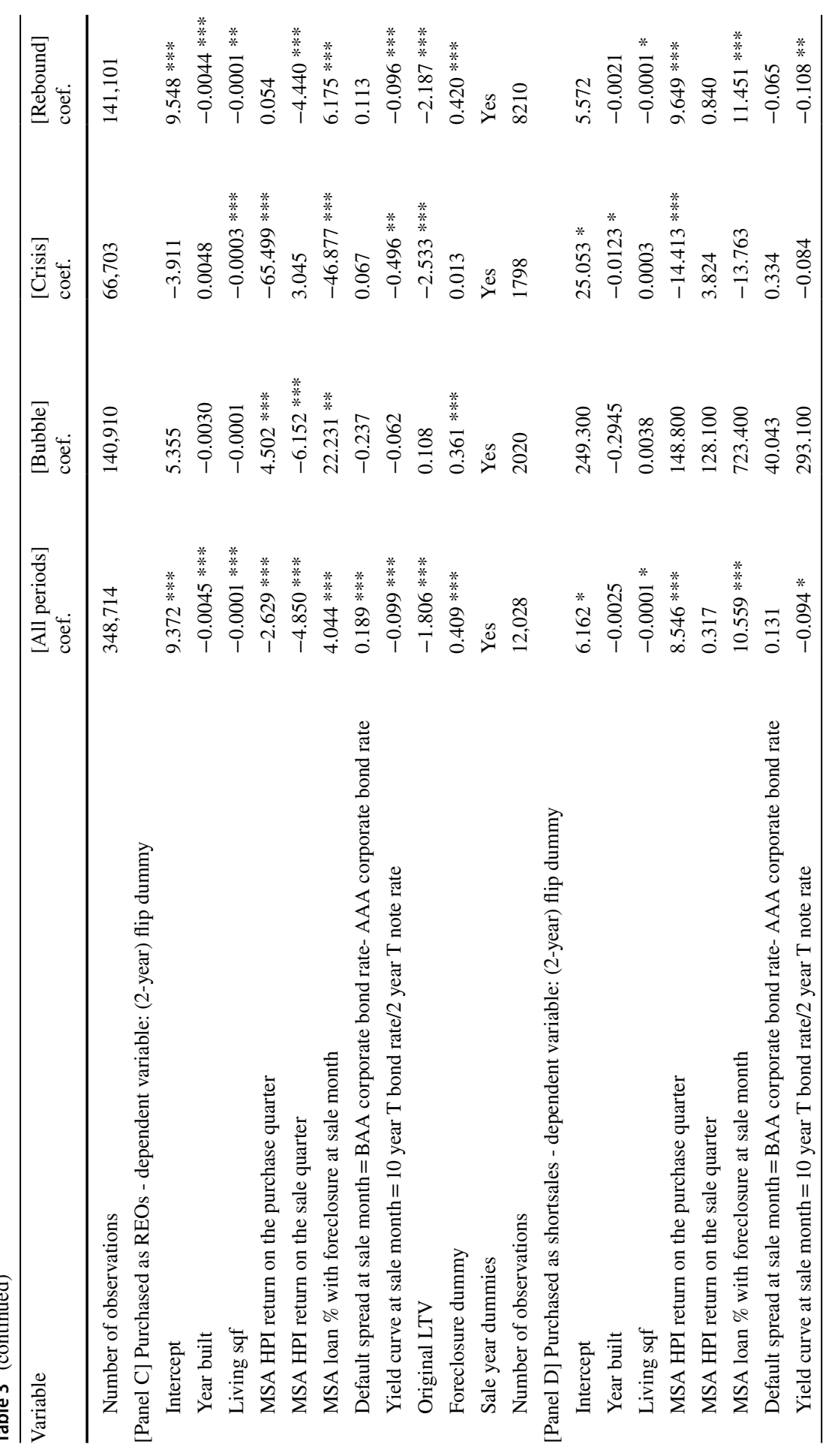




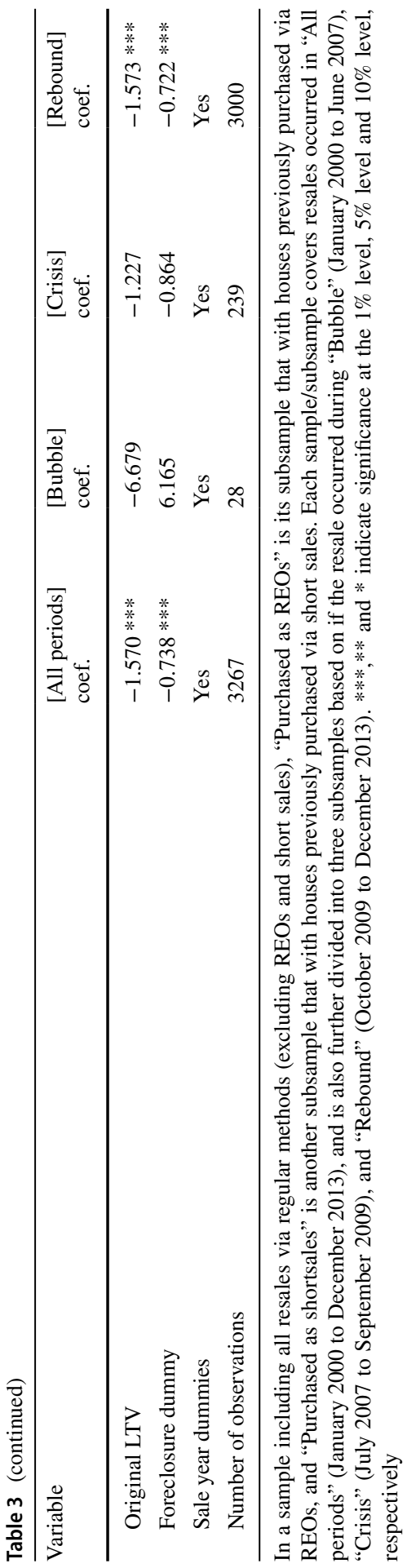


investors might react quickly to the arbitrage opportunities during the bubble. For the resales purchased as REOs, the results in Regression [3] generally resemble those in Panel C of Table 2; and for the resales purchased as shortsales, the results in Regression [4] generally resemble those in Panel D of Table 2.

Panel A2 of Table 4 highlights the coefficient and significance of the MSA HPI return on the quarter prior to the sale quarter in each of the four flip logit regressions. The results are generally in line with those of the MSA HPI return of the sale quarter reported in Table 3.

In summary, the arbitrage incentives for flips or attempted flips stay generally robust regardless of whether we lag or do not lag the arbitrage motivation variable by 1 quarter. Please note that we also try to lag the arbitrage motivation variable by more than 1 quarter, and the results are less consistent with those reported in Tables 2 and 3 with the lag term longer. We choose to pay most attention to the results with the 1-quarter lagged term due to the quick resale nature of the flipped houses.

\section{MSA Fixed Effects}

Another possible concern on our arbitrage factor proxy, the MSA-level HPI return, is that this variable may indicate multiple facts, such as MSA-specific development and MSA-specific resident characteristics. To address this concern, we conduct another robustness test to include MSA fixed effects to rule out the heterogeneity across MSAs and absorb other unobserved factors that may contaminate the estimations. The results are reported in Panels B1 and B2 of Table 4.

Panel B1 highlights the coefficient and significance of the MSA HPI return on the listing quarter in each of the four flip attempt logit regressions. Panel B2 of Table 4 highlights the coefficient and significance of the MSA HPI return on the sale quarter in each of the four flip logit regressions. Similar as that reported in Table 2, during the bubble period, arbitrage incentives play a strong role for flip sales of regular properties regardless of if flip is measured as a property resale in two years or in one year after the purchase, while the role does not exist for flip sales of properties acquired via REO. Due to the limitations on the number of observations, we cannot do the test for bubble-period flip sales of properties acquired via short sales. In summary, the arbitrage incentives for flips or attempted flips during bubble stay generally robust regardless of whether we control for the MSA fixed effects or not.

\section{MSA-Varying Periods}

Our main results are based on the MSA-consistent bubble, crisis and rebound periods. In practice, the dates and magnitudes of crisis might differ across MSAs. We hence conduct another robustness test by defining each MSA's periods based on its own housing market cycle patterns. By comparing the peak/bottom/rebound time gap between each city's S\&P Case-Shiller HPI and the S\&P Case-Shiller 20-City HPI, we adjust the periods for each MSA. For instance, Chicago HPI's bubble peak is 1 quarter later than the 20-City HPI bubble peak, so we adjust its crisis starting 
time from the July 2007 to October 2007. For brevity, the results of flip and attempt flip regressions are highlighted in Panels $\mathrm{C} 1$ and $\mathrm{C} 2$ of Table 4.

Results reported are very similar to Tables 2 and 3 when the cycle periods are defined uniformly for all MSAs in our sample. In addition, those unreported results also resemble those in Tables 2 and 3. Note that the outcomes for short sale transactions during the bubble can be ignored since we have only 51 observations available. Based on this analysis, we contend that our flip and flip attempt results are robust when periods are defined at the MSA-level.

\section{Rental and Redevelopment Options}

House investors often use houses to produce rental income so rental option values may influence resale timing and pricing decisions. In addition, house price movements can also be affected by the option to rebuild or expand existing properties (see, for instance, Clapp et al., 2013). Correspondingly, we develop another robustness test by adding in the flip/flip attempt regressions in Eq. (1) with variables to proxy for the values of rental option and redevelopment option. For the rental option value, we estimate it by the ratio between the rent annual growth rate and the home price annual growth rate, where the rent is measured by the MSA-level Consumer Price Index for All Urban Consumers - Rent of primary residence (not seasonally adjusted) from Federal Reserve Economic Data and the home price is measured again by the MSA HPI from FHFA. This rental option value is computed at the listing quarter for the flip attempt regressions and computed at the sale quarter for the flip regressions. For the redevelopment option value, we use MSA-level WRLURI (Wharton Residential Land Use Regulation Index) as a proxy. This index is composed of multiple factors, one of which is developers' costs of construction, so it is loosely related to the renovation costs (particularly if it is external renovations associated with using additional land), and hence negatively affects the redevelopment option value. The results for the 2-year flip/flip attempt regressions are highlighted in Panels D1 and D2 of Table 4.

After controlling rent and redevelopment option value factors, as in Tables 2 and 3 , the arbitrage incentive (proxied by the MSA HPI return) is influential for flips/ flip attempts during the bubble, and financial constraint (proxied by the foreclosure dummy) plays the strongest role during the crisis. In addition, we see that rent and redevelopment options affect flip attempts and flips inconsistently across periods.

Rent option value (proxied by the rent growth relative to price growth) reduces flips/flip attempts during the bubble, which is intuitive for the investors, who would prefer to keep the properties and rent them out instead of selling them when rent grows faster than prices. However, the relation is the opposite during the crisis and rebound, confirming that flippers might be more driven by arbitrage/investment in the bubble than in other periods. In the crisis and rebound, on the contrary, flips are more driven by financial constraints, so if rents drop less (or increase more) significantly than prices (that is, rental option value is higher), it would be easier to find (and bargain with) buyers (especially investors) in cold markets, encouraging more flips and making flips easier. 
Table 4 Highlights of robustness tests for flip attempt/flip logit regressions

[Panel A1] Results of flip attempt logit regressions with MSA HPI return lagged by 1 quarter

coefficient of MSA HPI return of the quarter prior to the listing quarter

Sample / dependent variable

$\begin{array}{llll}\text { [All periods] } & \text { [Bubble] } & \text { [Crisis] } & \text { [Rebound] } \\ 3.638 * * * & 0.362 * * * & 2.007 * * * & -0.522 * \\ 3.200 * * * & 0.061 & 8.423 * * * & 0.336 \\ -4.241 * * * & -6.165 * * * & 8.901 * * * & -4.363 * * * \\ -2.483 * * & -176.500 & -7.200 & -2.052 * *\end{array}$

[1] All regular sales / (2-year) flip attempt dummy

[2] All regular sales / 1-year flip attempt dummy

[3] Purchased as REOs / (2-year) flip attempt dummy

[4] Purchased as shortsales / (2-year) flip attempt dummy

[Panel A2] Results of flip logit regressions with MSA HPI return lagged by 1 quarter

coefficient of MSA HPI return of the quarter prior to the sale quarter

Sample / dependent variable

[1] All regular sales / (2-year) flip dummy

[2] All regular sales / 1-year flip dummy

[3] Purchased as REOs / (2-year) flip dummy

[4] Purchased as shortsales / (2-year) flip dummy

[All periods] [Bubble] [Crisis] [Rebound]

$3.823 * * * \quad 1.355 * * * \quad-0.691 * \quad-2.055 * * *$

$4.012 * * * \quad 1.794 * * * \quad 10.975 * * * \quad-0.106$

$\begin{array}{llll}-5.517 * * * & -6.327 * * * & 6.049 * & -5.770 * * *\end{array}$

$-2.870 * * * \quad-405.100 \quad 4.120 \quad-2.828 * * *$

[Panel B1] Results of flip attempt logit regressions with MSA fixed effects controlled

coefficient of MSA HPI return of the listing quarter

Sample / dependent variable

[1] All regular sales / (2-year) flip attempt dummy

[All periods] [Bubble] [Crisis] [Rebound]

$2.605 * * * \quad 1.327 * * * \quad 4.928 * * * \quad-0.916 * * *$

[2] All regular sales / 1-year flip attempt dummy

$2.916 * * *$

$1.825 * * *$

$6.202 * * *$

$-0.509 * * *$

[3] Purchased as REOs / (2-year) flip attempt dummy

[4] Purchased as shortsales / (2-year) flip attempt

$-2.785 * * * \quad-2.793 * * *$

$8.710 * * *$

$-3.704 * * *$ dummy

$-3.948 * * * \quad \mathrm{NA}$

$-3.345$

$-4.185 * * *$

[Panel B2] Results of flip logit regressions with MSA fixed effects controlled

coefficient of MSA HPI return of the sale quarter

\section{Sample / dependent variable}

[1] All regular sales / (2-year) flip dummy

[2] All regular sales / 1-year flip dummy

[3] Purchased as REOs / (2-year) flip dummy

[4] Purchased as shortsales / (2-year) flip dummy
[All periods] [Bubble] [Crisis]

$2.757 * * * \quad 2.887 * * * \quad 2.523 * * * \quad-2.481 * * *$

$3.028 * * * \quad 3.048 * * * \quad 1.912 * * * \quad-1.237 * * *$

$-3.839 * * * \quad-2.432 * * \quad 2.984 \quad-5.062 * * *$

$-4.309 * * * \quad \mathrm{NA} \quad 7.357$

$-4.519 * * *$

[Panel C1] Results of flip attempt logit regressions with MSA-varying periods

coefficient of MSA HPI return of the listing quarter

Sample / dependent variable

[All periods] [Bubble] [Crisis] [Rebound]

[1] All regular sales / (2-year) flip attempt dummy

3.194*** $\quad 0.229 * * \quad-0.068 \quad-1.701 * * *$

[2] All regular sales / 1-year flip attempt dummy

$3.460 * * *$

$0.907 * * *$

$5.389 * * *$

0.027

[3] Purchased as REOs / (2-year) flip attempt dummy

$-3.815^{* * * *}$

$-6.058^{* * * *}$

$13.429 * * *$

$-3.623 * * *$

[4] Purchased as shortsales / (2-year) flip attempt

$-0.948$

6.649

$-0.950$

$-0.531$ dummy

[Panel C2] Results of flip logit regressions with MSA-varying periods

coefficient of MSA HPI return of the sale quarter

Sample / dependent variable

[1] All regular sales / (2-year) flip dummy

[All periods] [Bubble] [Crisis] [Rebound]

$3.455^{* * *} \quad 1.487 * * *-3.054 * * *-2.668 * * *$

[2] All regular sales / 1-year flip dummy

$3.580 * * * \quad 1.849 * * * \quad 0.923 * \quad-0.843 * *$

[3] Purchased as REOs / (2-year) flip dummy

$-4.850 * * * \quad-5.613 * * * \quad 2.903 \quad-4.679 * * *$


Table 4 (continued)

[4] Purchased as shortsales / (2-year) flip dummy $\quad 0.317 \quad 0 \quad-76.097 \quad 3.732 \quad 0.704$

[Panel D1] Results of 2-year flip attempt logit regressions (considering alternative investment opportunities) coefficient

$\begin{array}{lllll}\text { Main independent variables } & \text { [All periods] } & \text { [Bubble] } & \text { [Crisis] } & \text { [Rebound] } \\ \text { MSA HPI return on the listing quarter } & 4.190^{* * *} & 1.884^{* * *} & -0.551 & -1.716^{* * *} \\ \text { forclosure dummy } & 0.427 * * * & 0.240^{* * *} & 0.597 * * * & 0.234^{* * *} \\ \begin{array}{l}\text { MSA rent growth relative to price growth on the } \\ \quad \text { listing quarter }\end{array} & 0.002 * * * & -0.005^{* * *} & 0.006^{* * *} & 0.004^{*} \\ \text { MSA WRLURI } & -0.022^{*} & -0.041^{* * *} & 0.013 & 0.147 * * * \\ \text { Number of observations } & 242,870 & 92,295 & 48,763 & 101,812\end{array}$

[Panel D2] Results of 2-year flip logit regressions (considering alternative investment opportunities)

\begin{tabular}{|c|c|c|c|c|}
\hline & coefficient & & & \\
\hline Main independent variables & [All periods] & [Bubble] & [Crisis] & [Rebound] \\
\hline MSA HPI return on the sale quarter & $4.420 * * *$ & $2.813^{* * *} *$ & $-3.968 * * *$ & $-2.735^{* * *}$ \\
\hline forclosure dummy & $0.491 * * *$ & $0.287 * * *$ & $0.613^{* * *} *$ & $0.301 * * *$ \\
\hline $\begin{array}{l}\text { MSA rent growth relative to price growth on the sale } \\
\text { quarter }\end{array}$ & $0.004 * * *$ & $-0.005^{* * *}$ & $0.004 * * *$ & $0.007 * * *$ \\
\hline MSA WRLURI & $-0.060^{* * *}$ & $-0.081 * * *$ & -0.009 & $0.183^{* * *}$ \\
\hline Number of observations & 242,938 & 92,353 & 48,763 & 101,822 \\
\hline
\end{tabular}

[Panel A1], [Panel A2], [Panel B1], [Panel B2], [Panel C1], [Panel C2]: In these regressions, additional independent variables in regressions reported in Tables 2 and 3 are also included although not shown here. "All regular sales" is a sample including all resales via regular methods (excluding REOs and short sales), "Purchased as REOs" is its subsample that with houses previously purchased via REOs, and "Purchased as shortsales" is another subsample that with houses previously purchased via short sales. Each sample/subsample covers resales occurred in "All periods" (January 2000 to December 2013), and is also further divided into three subsamples based on if the resale occurred during "Bubble" (January 2000 to June 2007), "Crisis" (July 2007 to September 2009), and "Rebound" (October 2009 to December 2013). $* * *, * *$ and $*$ indicate significance at the $1 \%$ level, $5 \%$ level and $10 \%$ level, respectively

[Panel D1], [Panel D2]: In these regression, additional independent variables in regressions reported in Tables 2 and 3 are also included. The sample includes all resales via regular methods (excluding REOs and short sales). It covers resales occurred in "All periods" (January 2000 to December 2013), and is also further divided into three subsamples based on if the resale occurred during "Bubble" (January 2000 to June 2007), "Crisis" (July 2007 to September 2009), and "Rebound" (October 2009 to December 2013). $* * *, * *$ and $*$ indicate significance at the $1 \%$ level, $5 \%$ level and $10 \%$ level, respectively

For the redevelopment option value, when it is smaller (that is, redevelopment is more difficult, proxied by a higher WRLURI index), flips/flip attempts are more likely in the rebound, less likely in the bubble, and unaffected in the crisis. Redevelopments such as renovations are probably more directly related to housing consumption than to arbitrages/investments. During the bubble, for owners (especially investors who do not have consumption need for housing anyway), when the renovation option is less valuable, it is more difficult for them to find buyers (who might care more about renovation values than flippers), reducing flip attempts/flips. During the crisis, financial constraints are the main concerns for flippers, who might not have money to renovate and face tighter credit markets so the renovation option value does not matter. During the rebound, flippers are more likely to be home consumers, 
who care about renovations and hence more likely to flip when the renovation option value is lower.

\section{Results on Flip Performance}

In this section, we report the results of property resale performance regressions as specified in Eqs. (2) and (3). We test Hypothesis 2, namely, that flip sales produce better returns than non-flips. In other words, the flip probability in regression (2) and the flip dummy in regression (3) positively affect flip performance. Regression (3) serves as the robustness test for regression (2), as the latter involves a two-stage method so might face the "error-in-model risk" if the first-stage results (from regression (1)) that the second-stage regressions rely on are inaccurate.

\section{Effects of Flip Probability on Performance}

We first run performance regressions based on Eq. (2). The dependent variable is the abnormal gain speed (recall that we are characterizing this quantity as alpha), which is the difference between the capital gain speed (i.e. the price appreciation per month) and our market benchmark measure, the MSA level FHFA housing price index change rate per month. The explanatory variable is the endogenized flip probability estimated from previous (2-year) flip or 1-year flip logit regressions. Results are summarized in Table 5.

Panel A shows results of performance regressions of properties originally purchased under any circumstances and the explanatory variable is the (2-year) flip probability generated from the flip regression for the relevant property type as reported in Panel A of Table 3. Across all three periods, we find that property resale performance is consistently increasing in the endogeneized flip propensity, with significance at the $1 \%$ level. Possible explanations for this over-performance are the following. (1) The owner of a primary residence house does need to find a sufficiently good opportunity to resell to offset the loss of capital gain exclusion in taxation. (2) The owner of an investment property may rent out the house until a good resale price is available. (3) A good flip return is partially consistent with the signaling theory in Chen and Rutherford (2012), who argue that a longer TOM signals a poorer house quality leading to a lower return, indicating that a flip that is usually accompanied by a shorter TOM might be rewarded with a higher return for its good-quality signaling effect.

We also note that the over-performance of flips is the largest in magnitude for resales occurring during the crisis (with the coefficient of flip propensity 0.25) and the smallest in the bubble (with the coefficient of flip propensity 0.14). This implies that flips outperform non-flips most significantly during the crisis. This is consistent with financially opportunistic flip transactions occurring during the downturn performing better than what we've characterized as arbitrage flips undertaken during a rising market. Another indirect inference could be that the signaling effect is stronger in a declining market, on which there are more distress 
sales and hence more uncertainty and worries about the quality of the houses for sale, in line with the argument in Anglin et al. (2003) that the signaling effect of TOM is stronger in a more uncertain housing market.

Panel B shows the same model of performance but now using as the explanatory variable the fitted value of the 1-year flip probability generated from the logistic regression reported in Panel B of Table 3. The predicted 1-year flip probability is still positive and statistically significant at the $1 \%$ level in all regressions, but its magnitude is much larger. Since a seller completing a 1-year flip on a primary-residence house not only loses the benefit of capital gains tax exclusion, but also needs to recover transaction costs and remodeling costs in a shorter time horizon, the 1-year flip must achieve a better performance than an otherwise comparable 2-year flip to compensate for this tax benefit loss. Our result confirms this effect. As in Panel A, the average outperformance of 1-year flips is much smaller in the bubble than in other two periods. This result confirms that in a rising market, a flip does not necessarily outperform a non-flip sale as much as in a down market (when the flips is more likely driven by financial constraints).

Panel $\mathrm{C}$ reports the results of performance regressions of properties originally purchased as REO with the explanatory variable, the (2-year) flip probability, predicted from the flip regression for these types of properties reported in Panel $\mathrm{C}$ of Table 3. Panel D shows the results of performance regressions of properties originally acquired as SS with the explanatory variable the flip probability predicted from the flip regression for these types of properties reported in Panel $\mathrm{D}$ of Table 3. Results show a generally more substantial over-performance of flips relative to non-flips than those exhibited in Panel A, evidenced by much larger magnitudes on the coefficient of the flip dummy. Results may be driven by the fact that those properties were originally purchased at low REO or SS prices. Consistent with the results in Panels A and B, the over-performance by flips is smallest during the bubble period. This provides further evidence that in a rising market (where a flip is more likely driven by arbitrage), a flip will not necessarily outperform a non-flip sale as much as in a down market. The signaling effect may also play a role here. Houses purchased as REO or SS may be more likely to have quality issues, but if those can be quickly addressed through repair or costeffective remodeling, good returns may follow.

Note that results in Table 5 are based on the endogenized flip probabilities generated from the first-stage regressions shown in Table 3. We also redo the secondstage analyses using alternative first-stage regression specifications that include different sets of controlling variable to address for multicollearity, and we find similar results. 


\section{Robustness Checks for Flip Performance}

\section{Exogenous Flips}

To avoid the error-in-model problem in the previous performance regressions based on regression (2) (due to possible inaccuracy of the first-stage regression results that regression (2) is based on), we also conduct a robustness test following regression (3). In particular, we estimate regressions of the performance variables on the flip dummies, controlling for property characteristics, local housing and mortgage market conditions, and national capital market conditions. Results appear in Table 6.

Panel A displays the results of performance regressions on properties originally purchased under any circumstances and the main explanatory variable is the (2-year) flip dummy. We also control for property and mortgage characteristics, local housing market conditions, and national capital market conditions. Across the three time periods, resale performance is consistently increasing in the flip dummy at the $1 \%$ significance level, with coefficients as $0.016,0.021$ and 0.040 , respectively. Variance inflation factors ("VIF") are 1.20, 1.13 and 1.09, respectively, closer to 1.0 than the VIF of most other explanatory variables, suggesting that the positive influence of flip to performance is unique relative to the influence of other explanatory variables. Results confirm that on average flippers did generate higher return rates than nonflippers during the same period. Interestingly, the coefficient of the flip dummy is again the smallest during the bubble, compared to other periods.

Panel B reports the results of performance regressions using as the explanatory variable the 1-year flip dummy, controlling for the same set of explanatory variables as in Panel A. The 1-year dummy has a significant and positive coefficient with a VIF close to 1.0. Compared to Panel A, it seems that the over-performance exhibited by the 1-year flips is more prominent than that of the 2-year flips. In particular, the estimated coefficient on the flip dummy (0.048) is more than twice the magnitude of the value $(0.023)$ when all the three periods are consolidated. This greater overperformance is consistent with that shown in Table 5. Recall that we argued that this pattern is consistent with the fact that 1-year flips must achieve a better performance than the 2-year flips in order to recover the transactions costs and remodeling costs more quickly, at least if the property is an owner-occupied primary residence.

Panel C and D show the analogous results for performance regressions on properties originally purchased as REOs and SS. The main explanatory variable is the 2-year flip dummy. Here we cannot present meaningful bubble period estimates for properties originally purchased as SS since there are only 28 observations. Most other regression results show greater over-performance by flips properties than when the properties are purchased mostly as regular sales shown in Panel A. Again, this may be driven by the fact that those properties were originally purchased at relatively low prices as REO and SS. Again, over-performance by flips is smaller during the bubble than during other two periods. This confirms that the outperformance of flips (to non-flip sales) in a rising market (where flips are more likely driven by arbitrage) is not necessary more significant than that in a down market (where flips are more likely driven by financial constraints). 
Table 5 Performance regression results

\begin{tabular}{|c|c|c|c|c|}
\hline Variable & $\begin{array}{l}\text { [All periods] } \\
\text { coef. }\end{array}$ & $\begin{array}{l}\text { [Bubble] } \\
\text { coef. }\end{array}$ & $\begin{array}{l}\text { [Crisis] } \\
\text { coef. }\end{array}$ & $\begin{array}{l}\text { [Rebound] } \\
\text { coef. }\end{array}$ \\
\hline \multicolumn{5}{|c|}{ [Panel A] All regular sales - dependent variable: abnormal gain speed } \\
\hline Intercept & $-0.047 * * *$ & $-0.076 * * *$ & $-0.128 * * *$ & $-0.093 * * *$ \\
\hline $\begin{array}{l}\text { 2-year flip probability (inferred from flip } \\
\text { regressions) }\end{array}$ & $0.096 * * *$ & $0.144 * * *$ & $0.247 * * *$ & $0.188 * * *$ \\
\hline Number of observations & 343,823 & 140,031 & 66,115 & 137,677 \\
\hline \multicolumn{5}{|c|}{ [Panel B] All regular sales - dependent variable: abnormal gain speed } \\
\hline Intercept & $-0.104 * * *$ & $-0.124 * * *$ & $-0.183 * * *$ & $-0.210 * * *$ \\
\hline $\begin{array}{l}\text { 1-year flip probability (inferred from flip } \\
\text { regressions) }\end{array}$ & $0.209 * * *$ & $0.243 * * *$ & $0.363 * * *$ & $0.420 * * *$ \\
\hline Number of observations & 343,823 & 140,031 & 66,115 & 137,677 \\
\hline \multicolumn{5}{|c|}{ [Panel C] Purchased as REOs - dependent variable: abnormal gain speed } \\
\hline Intercept & $-0.162 * * *$ & $-0.130 * * *$ & $-0.235 * * *$ & $-0.174 * * *$ \\
\hline $\begin{array}{l}\text { 2-year flip probability (inferred from flip } \\
\text { regressions) }\end{array}$ & $0.324 * * *$ & $0.250 * * *$ & $0.442 * * *$ & $0.352 * * *$ \\
\hline Number of observations & 10,574 & 1804 & 1656 & 7114 \\
\hline \multicolumn{5}{|c|}{ [Panel D] Purchased as short sales - dependent variable: abnormal gain speed } \\
\hline Intercept & $-0.180 * * *$ & -0.141 & $-0.203 * * *$ & $-0.220 * * *$ \\
\hline $\begin{array}{l}\text { 2-year flip probability (inferred from flip } \\
\text { regressions) }\end{array}$ & $0.347 * * *$ & $0.281 *$ & $0.359 * * *$ & $0.418 * * *$ \\
\hline Number of observations & 2756 & 26 & 217 & 2513 \\
\hline
\end{tabular}

The dependent variable is the abnormal gain speed, which is the difference between the gain speed and the MSA monthly FHFA HPI return rate, where the gain speed is measured as the capital gain rate by the sale time divided by the number of holding months by the sale time. "All regular sales" is a sample including all resales via regular methods (excluding REOs and short sales), "Purchased as REOs" is its subsample that with houses previously purchased via REOs, and "Purchased as shortsales" is another subsample that with houses previously purchased via short sales. Each sample/subsample covers resales occurred in "All periods" (January 2000 to December 2013), and is also further divided into three subsamples based on if the resale occurred during "Bubble" (January 2000 to June 2007), "Crisis" (July 2007 to September 2009), and "Rebound" (October 2009 to December 2013). ***** and * indicate significance at the $1 \%$ level, $5 \%$ level and $10 \%$ level, respectively

\section{Performance Incorporating Transaction Costs}

Due to the lack of transaction cost data and the fact that transaction cost is usually a very small percentage of the transaction volume, our house resale performance measurements in the previous analyses do not incorporate transaction costs. Will this make the results biased?

The address this concern, we conduct another robustness test by considering transaction costs in a simple way assuming that resales in our sample incur transaction costs that are estimated to be $6 \%$ of the transaction volumes, based on the fact that the prevailing commission fee (which is the major part of transaction costs) is at a $6 \%$ rate. Correspondingly, for a property resale, its gain speed is equal to (resale price (1-6\%) - purchase price)/purchase price/number of holding months. Similarly, 
the local housing market gain speed is equal to (the current local HPI (1-6\%) - last year's local HPI) /last year's local HPI/number of holding months that match the holding months of the resold property. The resold property's abnormal gain speed is the difference between its gain speed and the local housing market gain speed. We re-estimate Regression (2) using this performance measurement, and report the results in Table 7.

Compared the results in Tables 7 and 5 (where the transaction costs are ignored), we can see that they are very similar. This is intuitive: the transaction cost is only a small portion of transaction value, therefore incorporating it or not will not substantially affect the results. We do see that the coefficients of the flip probability measurements in all the panels in Table 7 are consistently smaller than those in Table 5. For instance, the coefficients of the 2-year flip probability (inferred from flip regressions) in the performance regressions reported in Panel A are $0.096,0.144,0.247$ and 0.188 for all-period, bubble, crisis and rebound samples, relatively, in Table 5. In Table 7, they are slightly reduced to 0.090 , $0.135,0.232$ and 0.176 , respectively, although all of them remain as $1 \%$ significant. This is also intuitive because the $6 \%$ resale commission rate is relatively more significant to a property's holding period performance when the holding period is shorter, hence generally reduces the property's holding period return more noticeably for a flipped house than for a non-flipped house. In other words, transaction costs slightly weaken the outperformance of the flipped houses over the non-flipped houses.

Again, to avoid the possible error-in-model problem, we re-estimate Regression (3) using this revised performance measurement, and the results (not reported here) are similar as in Table 6, confirming that our performance results hold when transaction costs are incorporated.

\section{Performance Incorporating Transaction Cost and Cost of Losing Tax Benefits}

Now let us consider not only transaction costs, but also the costs of losing the capital gains exclusion. Recall that a resale by owner-occupants will enjoy the capital gains exclusion (up to $\$ 500,000$ for a married couple) in taxation if the property is held for at least two years. Flipped houses are held for less than two years and hence lose this tax benefit. Unfortunately, we do not have the sellers' personal income tax bracket information, so can only use a simple way to roughly estimate the effects. In our next robustness test, we will re-estimate Regression (2) by adjusting the performance measurements to reflect not only the estimated transaction costs but also the estimated costs of losing tax benefits.

Specifically, for a property resale, its gain speed is equal to (resale price (1-6\%) - purchase price - proxy for capital gain income tax)/purchase price/number of holding months, where proxy for capital gain income tax is calculated as tax rate * (resale price (1-6\%) - purchase price - capital gain exclusion). Here, the capital gain exclusion is proxied by Min (500,000, resale price (1-6\%) -purchase price)** (1-2-year flip dummy). For simplicity, we assume that the local housing market gain speed is equal to (current local HPI (1-6\%) - last year's local HPI) * (1-tax rate) / 


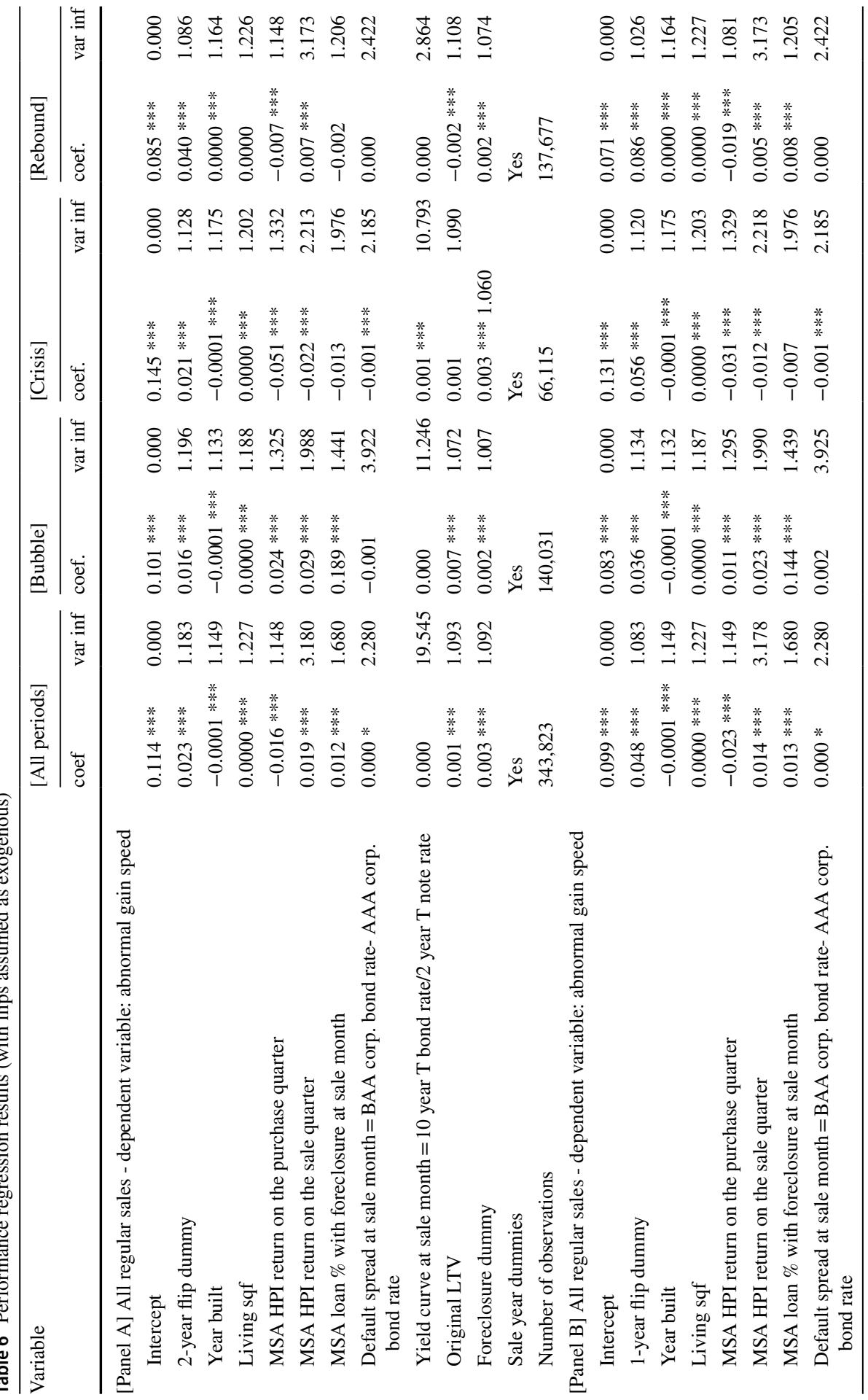




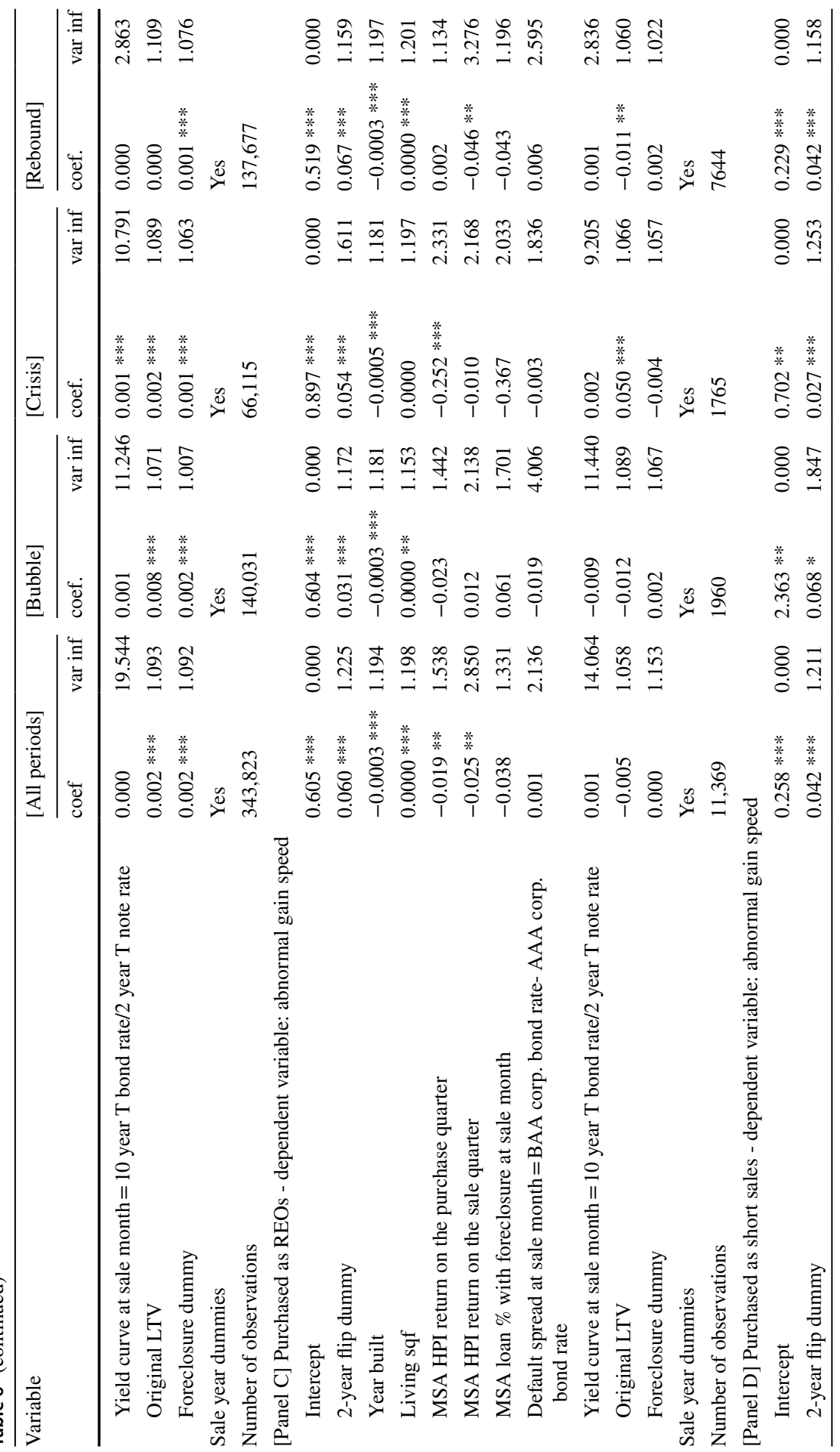




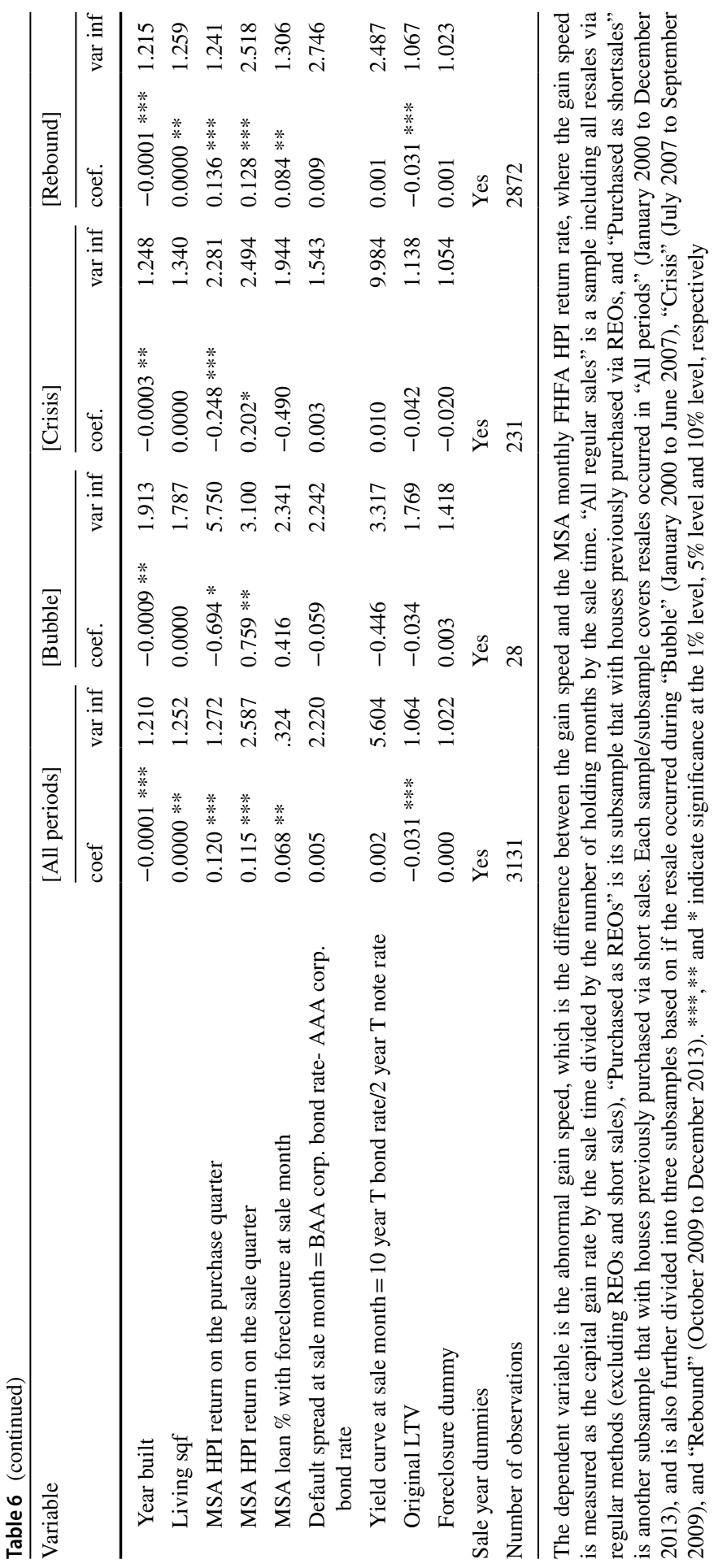


last year's local HPI/number of holding months that match the holding months of the resold property. ${ }^{22}$ Also for simplification, we assume a uniform tax rate $30 \% .^{23}$ Again, the resold property's abnormal gain speed is the difference between its gain speed and the local housing market gain speed. We re-estimate Regression (2) using this revised performance measurement, and report the results in Table 8.

Compared the results in Table 8 to those in Tables 5 and 7, we can see that they are still essentially similar. Since flipped houses on average face more transaction costs per holding month as well as additional costs of losing tax benefits, their outperformance against non-flipped houses are expected to be less pronounced than in Tables 5 and 7. This is confirmed by the results. For instance, we know earlier that the coefficients of the 2-year flip probability in the performance regressions reported in Panel A are slightly reduced from 0.096, 0.144, 0.247 and 0.188 (for all-period, bubble, crisis and rebound samples, relatively) in Table 5, to 0.090, 0.135, 0.232 and 0.176 in Table 7 . These are then further reduced to $0.083,0.086,0.162$ and 0.127 in Table 8 . Nevertheless, all of them remain as $1 \%$ significant in all three tables.

Again, to avoid the possible error-in-model problem, we also re-estimate Regression (3) using this revised performance measurement incorporating both transaction costs and taxation, and the results (not reported here) are similar as in Table 6, confirming that our performance results hold when transaction costs and tax effects are incorporated.

\section{MSA-Varying Periods}

Another robustness test for flip performance is to redo the regressions in Table 5 by defining three periods (bubble, crisis and rebound) based on each MSA's own housing market cycle as in the third robustness test for drivers for flips. Each MSA's periods are adjusted based on the time gaps between the peak/bottom/rebound time gap between this MSA's S\&P Case-Shiller HPI and the S\&P Case-Shiller 20-City HPI. The results are reported in Table 9, which are analogous to those in Table 5 when the periods are defined consistently across all MSAs.

Note that the over-performance of flips might lead us to rethink the use of the repeat sales indices. A well-known problem with repeat sales indices is the possibility of sample selection bias (see, for instance, Gatzlaff \& Haurin, 1997), that is, some types of houses traded more frequently in the market than other types will be over-represented in the repeat sales sample. When these types of houses exhibit different price changes, the repeat sales index can be biased. Given that flipped houses are traded more frequently than more typical properties, they may be over-represented in the repeat sales sample. Since these houses might perform better than other houses sold in the same period, they can make the local repeated sale price index biased upward.

\footnotetext{
22 Since the HPI data is measured as an index instead of as a dollar amount, its time-serial change cannot be compared to the $\$ 500,000$ capital gain standard for tax deduction, so we do not incorporate tax benefits in its calculation. However, the corresponding possible bias may have limited impacts on our study given that the local housing market capital gain speed is used as only a reference performance, and it is a reference for the performances of both flips and non-flips, the contrast of which is our main focus.

${ }^{23}$ We also try alternative tax rates, $20 \%$ and $40 \%$, and results are essentially similar as those under a $30 \%$ tax rate.
} 


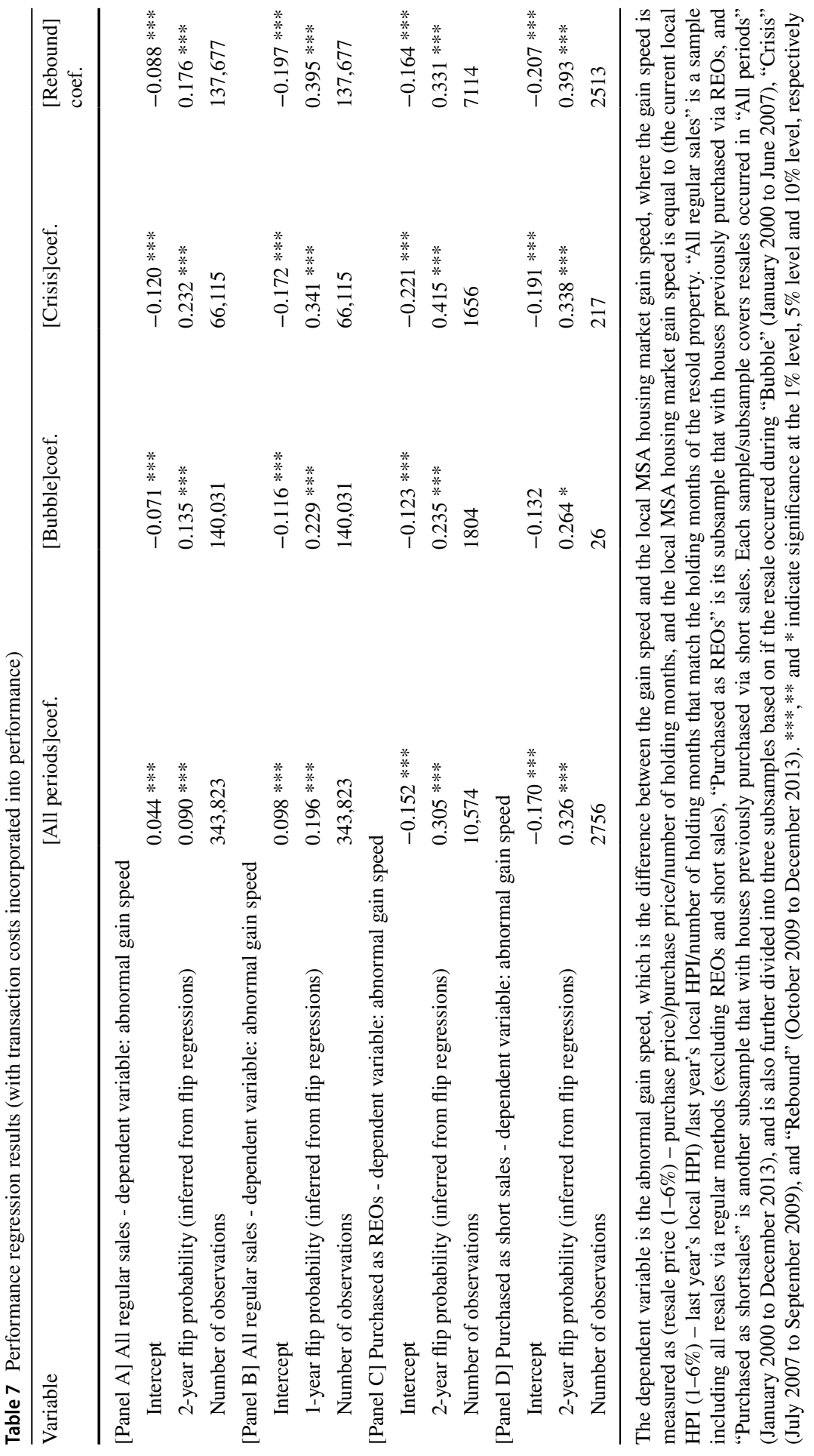




\section{Some Thoughts on Possible Selling Strategies}

Anglin et al. (2003) develop a measurement, DOP (Degree of Over-Pricing), to explore the relation between listing price and TOM. DOP is measured as the percentage difference between the actual list price and the expected list price estimated based on the observable property and market characteristics. They find that houses with smaller DOPs are sold faster, an evidence for the price-TOM tradeoff. This measurement might shed lights on possible resale selling strategies, by revealing whether flippers are taking unfair advantage of impatient sellers when purchasing the houses earlier or adding value based on comparative advantage. Based on Anglin et al. (2003), we estimate the expected purchase price, listing price and sale price from their pricing regressions that include commonly used hedonic pricing factors as explanatory variables and then calculate Degree of Over-Pricings for purchase price, listing price and sale price as their percent of differences from their expected prices. We study these using a subsample that includes resales in of one of the most frequently appearing MSAs in our sample, Chicago-Joliet-Naperville. In the pricing regressions, the dependent variable is log (price); the explanatory variables include house age, living space, land size, 1 to 5 bedroom number dummies, 1 to 3 full-bathroom number dummies, 1 to 2 half bathroom number dummies, 1 to 2 story number dummies, dummies for top 10 zip codes with most frequent resales, quarter dummies, and so on; and the regressions are with heteroscedasticity corrections. The results are highlighted in Fig. 2.

We find that among three types of resales, normal flips, same-month flips and nonflips, only $14.41 \%$ same-month flips are overpriced at listing prices ( $\mathrm{DOPl}>0)$ and the percentage is $31.33 \%$ for normal flips and $31.94 \%$ for non-flips. Similarly, the percentages of overpriced houses in sale prices are $15.32 \%, 31.68 \%$ and $31.98 \%$ for samemonth flips, normal flips and non-flips, respectively. These are generally in line with the findings in Anglin et al. (2003) that less overpriced houses are sold faster. In addition, we find similar overpricing patterns in purchase prices, with the percentages as $18.92 \%, 27.12 \%$ and $33.79 \%$ in the three resale types, suggesting that flipped houses can avoid more overpricing in listing and sale partially because they are also more likely to be purchased as good deals than non-flipped houses, and one of the reasons for good deals could be that these houses were originally sold by impatient sellers.

In fact, the majority of the resales (normal flips, same-month flips or non-flips) in our sample are in the $\mathrm{DOPb}<0, \mathrm{DOPl}<0, \mathrm{DOPs}<0$ category (that is, owners take advantage of low purchase prices, but also list and resell with discounts), but the fraction of this category is significantly larger in same-month flips than in normal flips and non-flips. The second most frequent category is the DOPb $>0, \mathrm{DOPl}>0, \mathrm{DOPs}>0$ category (that is, owners buy houses with premiums, and list and sell them with premiums). The prevalence of these two categories is not difficult to understand: a costly purchase may push the seller to pursue a high resale price in order to achieve a reasonable return from the resale; while a good-deal purchase will reduce this incentive, making a low resale price more likely to be acceptable to the seller.

It is interesting that the fraction of $\mathrm{DOPb}<0, \mathrm{DOPl}>0, \mathrm{DOPs}>0$ category (that is, owners take advantage of low purchase prices but relist and sell with high prices) is noticeably higher in normal flips than in same-month flips and non-flips, suggesting 


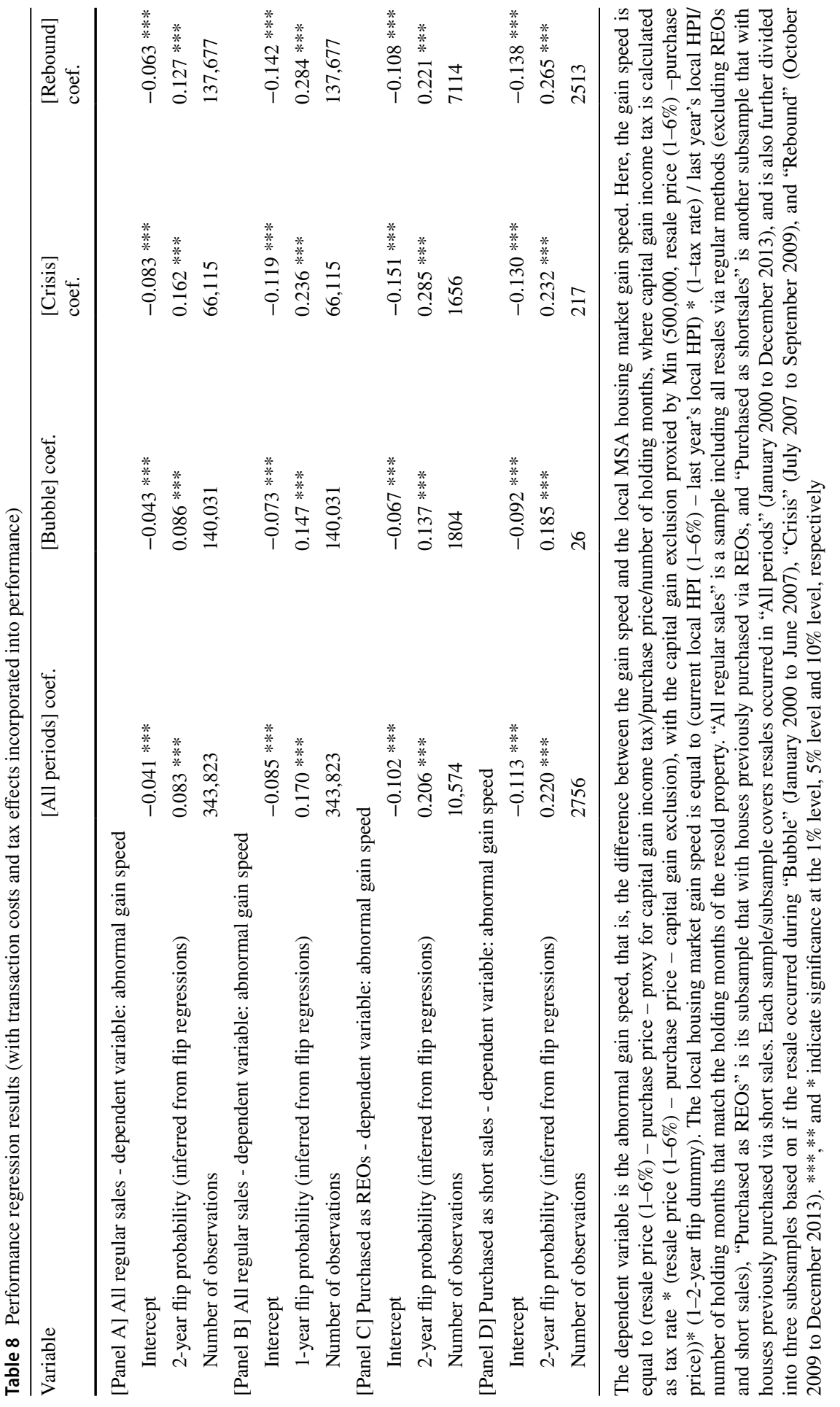


that normal flippers might be generally better at bargaining or truly add more values to the houses, ${ }^{24}$ or be able to list/sell the houses in stronger markets (with the last more likely, given $72 \%$ of normal flips in our sample occurring during the bubble). In contrast, the fraction is the lowest for the same-month flips, again probably because that most of them do not occur in bubble, as well as that they might not have enough time for bargaining or value-improving remodeling.

The fraction within the opposite category, the $\mathrm{DOPb}>0, \mathrm{DOPl}<0, \mathrm{DOPs}<0$ category (that is, where owners buy houses at a premium but list/sell at a discount, leading to bad deals) is overall the highest in non-flips (6.02\%), while the lowest in normal flips (3.25\%). As expected, bad deals are more concentrated in the crisis and rebound than in the bubble, with the fraction largest in same-month flips $(8.70 \%)$ during the crisis, and largest in non-flips (8.47\%) during the rebound.

Same-month flips with houses purchased at a premium exhibit inconsistent resale performances during both the bubble and the crisis. Their fraction of the $\mathrm{DOPb}>0, \mathrm{DOPl}<0$, DOPs $>0$ category (that is, owners plan for bad deals but end up with sale premiums probably because the markets turned out strong) during the bubble is substantially higher than those of normal flips and non-flips (5.45\% as versus $0.63 \%$ and $0.72 \%$ ), while their fraction of the $\mathrm{DOPb}>0, \mathrm{DOPl}>0$, DOPs $<0$ category (that is, owners buy houses at premiums and relisting them at premiums too, but end up cutting prices, resulting in bad deals) is much higher in crisis ( $4.35 \%$ as versus $0.67 \%$ and $1.47 \%$ ). These results indicate that agents may have some ways to profit from access to information (e.g. continuous access to MLS data in real time), but certainly not in all the periods. Recall that in the section for flip attempts, we find that agents reacted quickly to reduce losses during the crisis period. However, this kind of quick reaction seems to actually lead to larger losses.

\section{Conclusion}

Using nationally representative data created by merging public records and MLS data on single-family house sale transactions, we explore factors that might drive short term housing trades ("housing flips") across three very different periods in housing market: bubble, crisis and rebound. We ask whether flip sales outperform non-flip sales in terms of returns and excess returns (defined as return rate in excess of the local market average rate of appreciation). We provide evidence that flips are strongly associated with arbitrage incentives in a booming housing market and strongly associated with financial constraints in a down market. Moreover, flip sales produce better performance than non-flips and this pattern is stronger during the crisis than during the bubble. Higher returns and excess returns occur during the crisis period, as bravery in terms of buying at "beaten-down" prices is rewarded. Results are robust to our definition of flip holding period (1-year or 2-year), although results are stronger for 1-year holding periods.

\footnotetext{
24 An investor may buy a house, make renovations/improvements, and profit by selling for more than the cost of the improvements. However, when the holding period is shorter, it is more difficult for a flipper to recover these improvement costs. We do not have any data on actual renovation costs.
} 


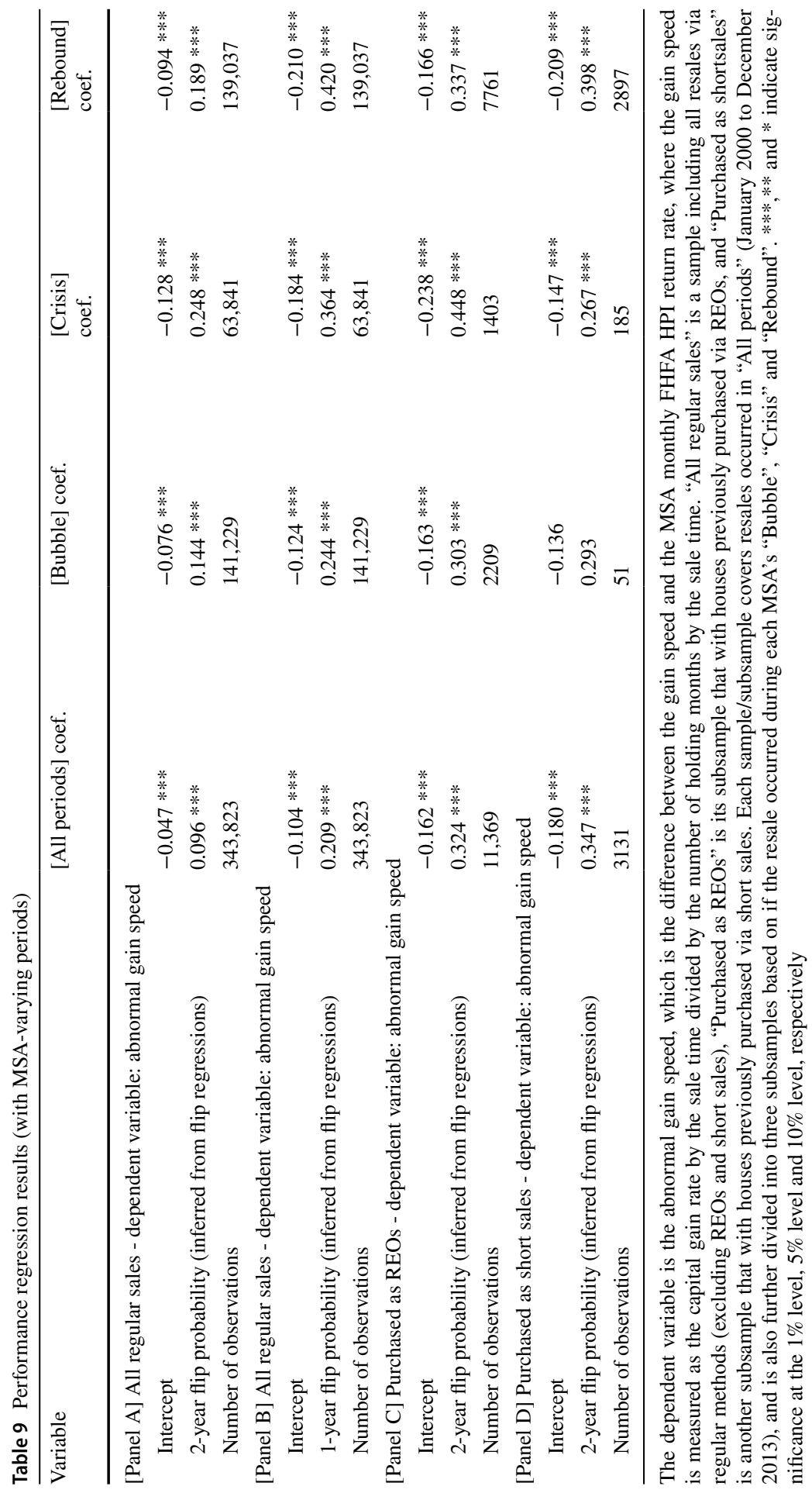



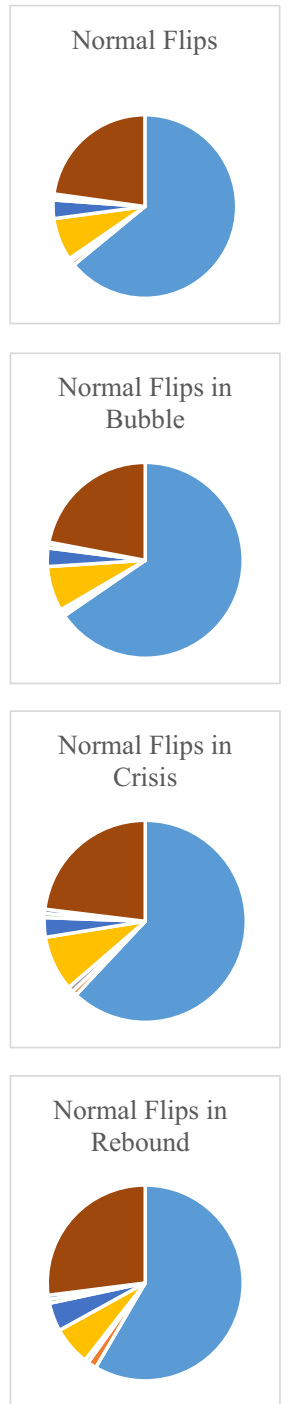
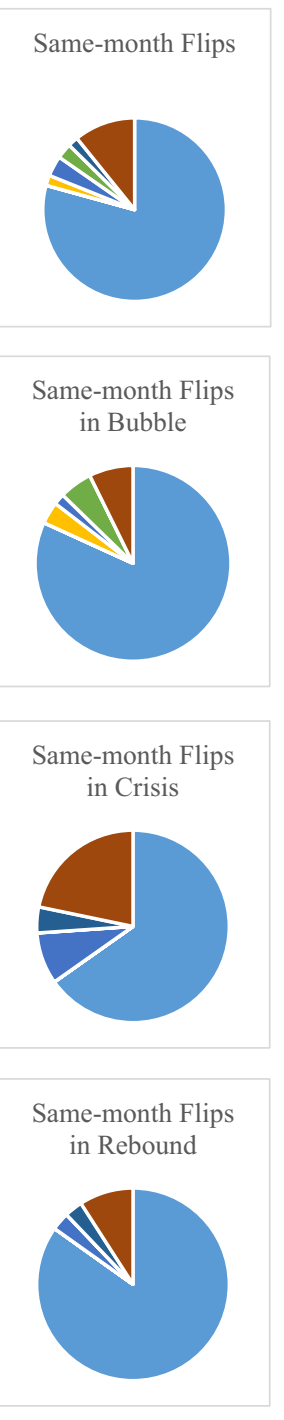

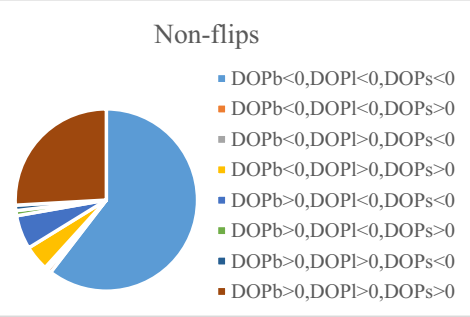

Non-flips in Bubble
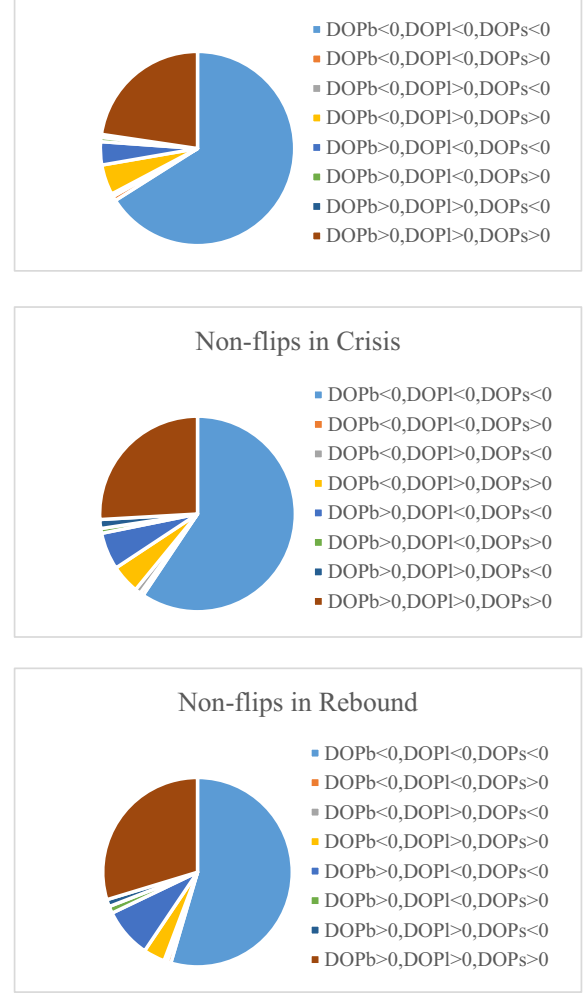

Fig. 2 Degree of Over-Pricing for Resales in Chicago-Joliet-Naperville. Using the data of one of the most frequent MSAs in our sample, Chicago-Joliet-Naperville, we estimate the expected purchase price, listing price and sale price from their pricing regressions, and then calculate the Degree of Over-Pricings for purchase price $\mathrm{DOPb}$, for listing price DOPl, and for sale price DOPs, as their percent differences from their expected prices. The explanatory variables in the pricing regressions include house age, living space, land size, 1 to 5 bedroom number dummies, 1 to 3 full-bathroom number dummies, 1 to 2 half bathroom number dummies, 1 to 2 story number dummies, dummies for top 10 zipcodes with most frequent resales, quarter dummies, and so on. Among all resales via regular methods (excluding REOs and short sales), "Normal flips" is a subsample that with houses resold within 2-Year from Purchases (excluding same-month resales), "Same-month flips" is a subsample that with houses resold within the same-month of purchases, and "Non-flips" is a subsample that with houses resold after 2 years of purchases. Each subsample is further divided into three subsamples based on if the resale occurred during "Bubble" (January 2000 to June 2007), "Crisis" (July 2007 to September 2009) or "Rebound" (October 2009 to December 2013) 
These results persist whether we view the flip as endogenously or exogenously determined, or whether we consider or ignore transaction costs and tax effects.

Patterns for properties acquired as REO or shortsales are quite different. In particular, over-performances (i.e., excess returns for flips over non-flips) are greater for REO or shortsales properties than for properties purchased regularly, mostly because acquisition costs were low. We also find that agent flips (defined as house flips within a month of purchase) tend out to perform worse than other flips, underscoring the difficulty of anything to approach pure arbitrage in the high transaction cost housing market. We acknowledge, however, a very small sample for this type of transaction.

Housing flip transactions are occasionally blamed for exacerbating the boom and bust in markets such as coastal California and Florida, where ensuing foreclosure waves harmed both borrowers and lenders. To the extent the phenomenon reappears, we hope the analysis presented here will assist housing market participants and regulators in tamping down what appears to be a recurrent mania. Future research might explore the effect of flip transactions on neighborhoods, including spillover effects in local housing markets. In addition, if the seller characteristic data is available, we can explore how differential selection bias and behaviors across neighborhoods within MSAs affect the frequency and performance of local flips. Our extended research topics include how flips affect house transactions in the neighborhood and how flips affect the same properties' future sale and price trajectory.

Acknowledgments We acknowledge helpful comments from the referee from Journal of Real Estate Finance \& Economics, Yen-Jong Chen, Benjamin S. Kay, Jessica Shui, Tammy Schlosky, Yu Shi Ming, Timo Rothovius, and participants of 2018 American Real Estate and Urban Economics Association National Conference, 2018 Asian Real Estate Society Annual Conference, 2018 Global Chinese Real Estate Congress Annual Conference, 2018 Financial Management Association Annual Meeting, and 2019 Winter Conference of the Multinational Finance Society.

Funding This research is supported by the 2013 CoreLogic Research Grant.

Data Availability Not applicable.

Code Availability Not applicable.

\section{Declarations}

Ethics Approval Not applicable.

Consent to Participate Not applicable.

Consent for Publication The undersigned authors, with the consent of all authors, hereby assign to Journal of Real Estate Finance and Economics, the copyright in this paper to be transferred, including supplemental tables, illustrations or other information submitted in all forms, in all languages and format, effective when and if the paper is accepted for publication.

Conflicts of Interest/Competing Interests Not applicable.

Open Access This article is licensed under a Creative Commons Attribution 4.0 International License, which permits use, sharing, adaptation, distribution and reproduction in any medium or format, as long as you give appropriate credit to the original author(s) and the source, provide a link to the Creative 
Commons licence, and indicate if changes were made. The images or other third party material in this article are included in the article's Creative Commons licence, unless indicated otherwise in a credit line to the material. If material is not included in the article's Creative Commons licence and your intended use is not permitted by statutory regulation or exceeds the permitted use, you will need to obtain permission directly from the copyright holder. To view a copy of this licence, visit http://creativecommons.org/ licenses/by/4.0/.

\section{References}

Anglin, P., Rutherford, R., \& Springer, T. (2003). The trade-off between the selling Price of residential properties and time-on-the-market: The impact of Price setting. Journal of Real Estate Finance and Economics, 26(1), 95-111.

Chen, J., \& Rutherford, R. (2012). Quality \& Time-on-the-Market in residential markets. Journal of Real Estate Finance and Economics, 44(3), 414-428.

Clapp, J. M., Eichholtz, P., \& Lindenthal, T. (2013). Real option value over a housing market cycle. Regional Science and Urban Economics, 43(6), 862-874.

Depken, C. A., Hollans, H., \& Swidler, S. (2009). An empirical analysis of residential property flipping. Journal of Real Estate Finance and Economics, 39(3), 248-263.

Gatzlaff, D. H., \& Haurin, D. R. (1997). Sample selection bias and repeated-sales index. Journal of Real Estate Finance and Economics, 14(1-2), 33-50.

He, X., Lin, Z., Liu, Y., \& Seiler, M. (2020). Search benefit in housing markets: An inverted U-shaped price and TOM relation. Real Estate Economics, 48(3), 772-807.

Knight, J. (2002). Listing Price, time on market and ultimate selling Price: Causes and effects of listing Price changes. Real Estate Economics, 30(2), 213-237.

Kwok, H.-H., \& Tse, C.-Y. (2006). Estimating Liquidity Effects in the Housing Market. University of Hong Kong Working Paper, 1-26.

Lin, Z., \& Liu, Y. (2008). Real estate returns and risk with heterogeneous investors. Real Estate Economics, 36(4), 753-776.

Rutherford, J., Rutherford, R., Strom, E., \& Wedge, L. (2017). The subsequent market value of former REO properties. Real Estate Economics, 45(3), 713-760.

Seagraves, P., \& Gallimore, P. (2013). The gender gap in real estate sales: Negotiation skill or agent selection? Real Estate Economics, 41(3), 600-631.

Taylor, C. R. (1999). Time-on-the-market as a sign of quality. Review of Economics Studies, 66(3), $555-578$.

Publisher's Note Springer Nature remains neutral with regard to jurisdictional claims in published maps and institutional affiliations. 